\title{
Article \\ Effect of Magnesium Fertilization Systems on Grain Yield Formation by Winter Wheat (Triticum aestivum L.) during the Grain-Filling Period
}

\author{
Witold Grzebisz *(i) and Jarosław Potarzycki \\ Department of Agricultural Chemistry and Environmental Biogeochemistry, Poznan University of Life Sciences, \\ Wojska Polskiego 28, 60-637 Poznan, Poland; jaroslaw.potarzycki@up.poznan.pl \\ * Correspondence: witold.grzebisz@up.poznan.pl
}

Citation: Grzebisz, W.; Potarzycki, J. Effect of Magnesium Fertilization Systems on Grain Yield Formation by Winter Wheat (Triticum aestivum L.) during the Grain-Filling Period. Agronomy 2022, 12, 12. https:// doi.org/10.3390/agronomy12010012

Academic Editor:

Francesco Montemurro

Received: 26 November 2021 Accepted: 17 December 2021 Published: 22 December 2021

Publisher's Note: MDPI stays neutral with regard to jurisdictional claims in published maps and institutional affiliations.

Copyright: (C) 2021 by the authors. Licensee MDPI, Basel, Switzerland. This article is an open access article distributed under the terms and conditions of the Creative Commons Attribution (CC BY) license (https:// creativecommons.org/licenses/by/ $4.0 /)$.

\begin{abstract}
The application of magnesium significantly affects the components of the wheat yield and the dry matter partitioning in the grain-filling period (GFP). This hypothesis was tested in 2013, 2014, and 2015. A two-factorial experiment with three rates of magnesium $\left(0,25,50 \mathrm{~kg} \mathrm{ha}^{-1}\right)$ and four stages of Mg foliar fertilization (without, $\mathrm{BBCH} 30,49 / 50$, two-stage) was carried out. Plant material collected at BBCH: 58, 79, 89 was divided into leaves, stems, ears, chaff, and grain. The wheat yield increased by 0.5 and $0.7 \mathrm{tha}^{-1}$ in response to the soil and foliar $\mathrm{Mg}$ application. The interaction of both systems gave $+0.9 \mathrm{tha}^{-1}$. The $\mathrm{Mg}$ application affected the grain yield by increasing grain density (GD), wheat biomass at the onset of wheat flowering, durability of leaves in GFP, and share of remobilized dry matter (REQ) in the grain yield. The current photosynthesis accounted for $66 \%$ and the REQ for $34 \%$. The soil-applied Mg increased the REQ share in the grain yield to over $50 \%$ in 2014 and 2015. The highest yield is possible, but provided a sufficiently high GD, and a balanced share of both assimilate sources in the grain yield during the maturation phase of wheat growth.
\end{abstract}

Keywords: wheat parts; biomass; biomass partitioning; dry matter remobilization; current photosynthesis; stages of grain growth

\section{Introduction}

Progressive growth in the human population is a fact, and it will reach at least nine billion by 2050 [1]. The food gap can be covered by several actions, but the most important and effective are both the increase in yields of crops, and area of arable soils. In the past, the first factor was responsible for $55-60 \%$ increase in the food production [2]. Wheat is one of the most important crops in the world that can cover the food gap. Grain is used as the staple source for production of bread [3]. The yielding potential of this crop is high. The world record, set in New Zealand in 2020, is $17.398 \mathrm{t} \mathrm{ha}^{-1}$ [4]. The wheat yield potential assessed for the leading producers in Europe, such as Ireland, Germany, and France, is at the level of 12.7, 11.1, and $9.9 \mathrm{t} \mathrm{ha}^{-1}$ [5]. The actual yields for these countries are lower, and for 2015-2019, amounted to $9.65 \pm 0.86,6.92 \pm 1.03$, and $7.49 \pm 0.52 \mathrm{t} \mathrm{ha}^{-1}$, respectively. The world average yield of wheat is drastically lower and amounts to only $3.2 \mathrm{t} \mathrm{ha}^{-1}$ [6]. It can be, therefore, concluded that the exploration of the yielding potential of wheat on a global scale is not sufficient.

The grain yield of wheat is the result of two basic elements of the yield structure, i.e., the number of grains per unit area (grain density, acronym-GD) and the weight of grains, expressed as 1000 grain weight (TGW). Grain density is an aggregate yield parameter, defined by basic yield structure components such as ear density (ED) and grain number per ear (GR) [7]. The number of fertile flowers per plants develops during a long period of an ear development. This process is the most intensive in the boot phase (BBCH 40-49). The partition of assimilates, necessary for the balanced growth of vegetative (leaves and stems) and reproductive wheat organs (spike), is a prerequisite for a high grain yield. In this phase, it should be 50:50 [8]. The increase in the yield wheat, and cereals in general, 
is a derivative of the improvement of this particular yield trait. Most of the study related to breeding of new wheat varieties stresses that GD is the yield trait decisive for the grain yield increase $[9,10]$. At the same time, it was observed that GD is highly sensitive to environmental conditions, including not only weather, but also supply of nitrogen to plants in critical stages of yield formation [11-13]. Grain growth begins approximately 12 days after the beginning of flowering $[7,14]$. The final TGW is a result of the rate of carbohydrate accumulation in the enlarging grain and the length of the grain-filling phase (GFP) [9]. The key environmental factor influencing the TGW is the temperature during the GFP. Its increase, on the one hand, increases the rate of carbohydrate transport to enlarging grains, and on the other hand, it shortens the activity of leaves, producing assimilates [15]. The ear weight at the end of wheat heading, just before flowering, is used by breeders as an important indicator of the potential grain density $[13,16]$. This particular period of wheat growth is, therefore, decisive for wheat grain yield. In practice, the utilization of the yield potential of wheat by a farmer depends on two sets of factors. The first is the yield potential of the variety. The second set of factors is closely related to the environmental and agronomic conditions, which affect partitioning of assimilates between those organs, which are responsible for GD $[13,17,18]$.

The growth rate of grains, as the factor determining the grain yield, depends on two sources of carbohydrate. The first, known as current photosynthesis (CP), concerns the actual photosynthetic activity of physiologically active parts of the plant. The second one, termed as remobilization, concerns the carbohydrate reserves accumulated by the plant in the vegetative parts during the preflowering stages of its growth. The share of remobilized assimilate reserves in the final grain weight ranges from about $20 \%(5-25 \%)$ under optimal conditions to as much as $60 \%$ under stressful growth conditions $[19,20]$. High temperature and simultaneous drought during the grain-filling period are the key environmental factors accelerating the grain growth rate. At the same time, they reduce the activity and longevity of leaves and ears, leading finally to TGW decrease [21-24].

The existence of the yield gap, regardless of the scale of the assessed area, i.e., field, farm, region, or country, clearly indicates the presence of factors, limiting the use of the yielding potential of wheat. The essence of the farmer's use of the production potential of modern wheat varieties is the high efficiency of two key factors, i.e., water and nitrogen, which are not complementary [25]. Water productivity is a good indicator of the wheat yield gap [26]. In Ireland, the actual productivity of water is $1.89 \mathrm{~kg} \mathrm{~m}^{-3}$, and the potential is $2.53 \mathrm{~kg} \mathrm{~m}^{-3}$. In Poland, these two values are 1.04 and $1.49 \mathrm{~kg} \mathrm{~m}^{-3}$, respectively. The yield gap based on water productivity is $0.43 \mathrm{tha}^{-1}$ and $5.23 . \mathrm{t} \mathrm{ha}^{-1}$ for both these two countries, respectively. These two figures clearly show the presence of coarse and fine factors, limiting efficiency of these two mega-drives to the grain yield of wheat.

The production of wheat on suitable soil, i.e., requiring a fine modulation of its fertility, largely depends on the management of three main nutrients, i.e., nitrogen $(\mathrm{N})$, phosphorus $(\mathrm{P})$, and potassium $(\mathrm{K})$. In such cases, the nutritional status of the wheat can be effectively controlled, based on the concept of the fertilizer management principles [27]. This concept is based on determining the correct (i) dose, (ii) time, (iii) source, and (iv) a method of fertilizer application. In fact, based on the in-season development of wheat yield components, these rules apply to nitrogen. There are numerous scientific papers explaining the response of wheat to each of these four operational measures of nitrogen fertilization management $[28,29]$.

The yield stagnation is observed in the leading wheat producers, irrespective of the world region [2,30]. Regression models, such as quadratic or quadratic-plateau, are often used to determine the response of the wheat yield to $\mathrm{N}$ doses. Both models can signal and even determine the appearance of an ineffective range of $\mathrm{N}$ fertilizer applied. This yield gap can be, at least partially, covered by a balanced supply of P and K. It does not depend, however, on the direct application of these nutrients, but on the level of soil fertility [31,32]. The productivity of fertilizer nitrogen in wheat also depends on the nutritional status of the plant with other nutrients [33]. One of them is magnesium [34]. The effect of Mg 
application to cereals, as shown by a meta-analysis by Wang et al. [35], reached 8.2\%, being, however, significantly lower compared to grasses $(10.6 \%)$, and especially to fruits $(12.5 \%)$.

The aim of the study was to evaluate the effect of the magnesium fertilization system on the grain yield and grain yield components of wheat, against the background of its impact on the partitioning of dry matter in the period of grain formation and filling.

\section{Materials and Methods}

\subsection{Experimental Site}

A field experiment was carried out at Jarosławiec $\left(52^{\circ} 15^{\prime} \mathrm{N}, 17^{\circ} 32^{\prime} \mathrm{E}\right.$, Poland $)$ on soil originated from sandy loam, classified as Albic Luvisols (Neocambic) [36]. The content of organic matter $\left(\mathrm{C}_{\mathrm{org}}\right)$ in a $0.0-0.3 \mathrm{~m}$ layer ranged during the study from $21 \pm 0.1$ to $25 \pm 0.9 \mathrm{~g} \mathrm{~kg}^{-1}$ soil (losses on ignition). Soil reaction $(\mathrm{pH})$ was in the neutral range $(1 \mathrm{M}$ $\mathrm{KCl})$. The content of available nutrients, measured before the application of fertilizers, was in general good for $\mathrm{P}$ and sufficient for $\mathrm{K}$ and $\mathrm{Mg}$. The amount of the mineral $\mathrm{N}\left(\mathrm{N}_{\min }\right)$ determined in a $0.0-0.9 \mathrm{~m}$ layer was high in the first two growing seasons, and medium in the third (Table 1).

Table 1. Soil characteristics of the experimental plots during 2012-2015 growing seasons.

\begin{tabular}{|c|c|c|c|c|c|c|}
\hline \multirow{2}{*}{ Year } & Soil Layer & $\mathrm{pH}$ & $P^{1}$ & $\mathrm{~K}^{1}$ & $\mathrm{Mg}^{2}$ & $\mathbf{N}_{\min }$ \\
\hline & $(\mathrm{cm})$ & $1 \mathrm{M} \mathrm{KCl}$ & & $\mathrm{mg} \mathrm{kg}^{-1}$ soil & & $\mathrm{kg} \mathrm{ha}^{-1}$ \\
\hline \multirow{2}{*}{$2012 / 2013$} & $0-30$ & \multirow{2}{*}{6.5} & $63.2^{1} \mathrm{M}^{3}$ & $157.7 \mathrm{M}$ & $33.2 \mathrm{H}$ & \multirow[b]{2}{*}{$76^{4}$} \\
\hline & $30-60$ & & $59.7^{1} \mathrm{M}$ & $107.9 \mathrm{M}$ & $25.3 \mathrm{M}$ & \\
\hline \multirow{2}{*}{$2013 / 2014$} & $0-30$ & \multirow{2}{*}{6.7} & $91.6^{1} \mathrm{H}$ & $168.0 \mathrm{M}$ & $30.2 \mathrm{M}$ & \multirow{2}{*}{74} \\
\hline & $30-60$ & & $91.6^{1} \mathrm{H}$ & $153.6 \mathrm{M}$ & $24.7 \mathrm{M}$ & \\
\hline \multirow{2}{*}{$2014 / 2015$} & $0-30$ & \multirow{2}{*}{6.6} & $87.2^{1} \mathrm{H}$ & $182.6 \mathrm{H}$ & $24.1 \mathrm{M}$ & \multirow{2}{*}{57} \\
\hline & $30-60$ & & $95.9^{1} \mathrm{H}$ & $149.9 \mathrm{M}$ & $30.2 \mathrm{M}$ & \\
\hline
\end{tabular}

${ }^{1}$ Egner-Riehm method; ${ }^{2}$ Schachtschabel method; ${ }^{3}$ Classes of the available nutrient content: $\mathrm{M}-$ medium, $\mathrm{H}$-high; ${ }^{4}$ Layer 0-90 cm (measured in $0.01 \mathrm{M} \mathrm{CaCl}_{2}$ ).

\subsection{Weather Conditions}

The weather conditions were very variable in the consecutive growing seasons (Figure 1). The beginning of spring, with the exception of 2012/2013, favored the growth of wheat. In 2013, negative temperatures in the first two decades of March stopped plant growth. In all years of study, temperatures during the flowering and grain filling were within the ranges optimal for the yield development. The sum of rainfall during the spring growing season was as follows: $2013-299.4 \mathrm{~mm}, 2014-285.2 \mathrm{~mm}$, and 2015-265 mm. In 2015, a shortage of rainfall was revealed, which covered three main phases of wheat development, ranging from shooting to early flowering. The sum of rainfall in this period was $37.6 \mathrm{~mm}$, while in 2013 it reached $88.8 \mathrm{~mm}$, and in $2014,92.6 \mathrm{~mm}$.

\subsection{Experimental Design}

The field experiment was arranged as a two-factor split-plot design, replicated four times:

(1) Soil-applied magnesium (Mgs): 0, 25, $50 \mathrm{~kg} \mathrm{Mg} \mathrm{ha}^{-1}$

(2) Foliar-applied magnesium (Mgf):

a. Without application.

b. Applied at the BBCH 30 stage (I).

c. Applied at the BBCH 49/50 stage (II),

d. Double-stage application (I+ II). 


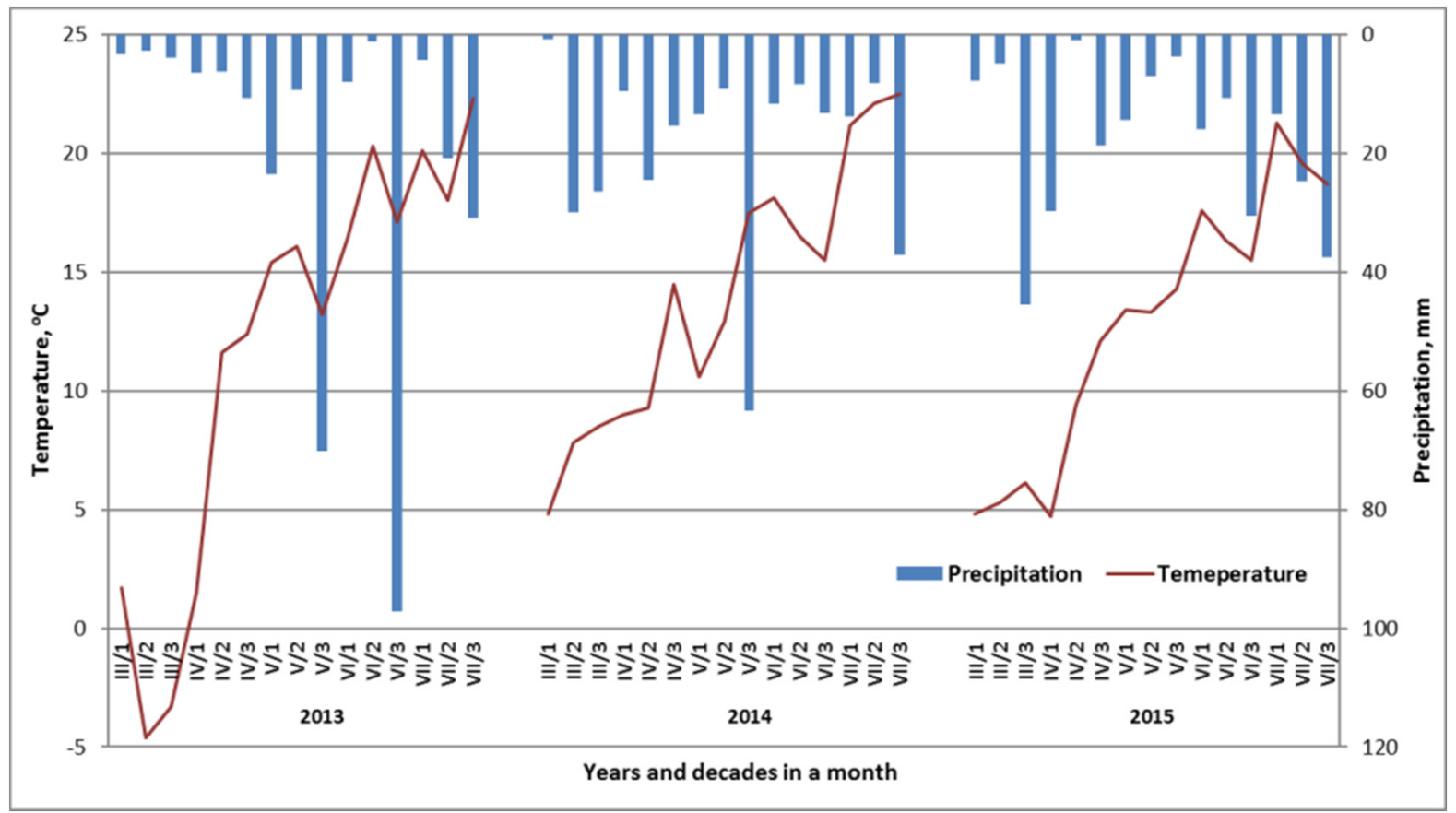

Figure 1. Weather conditions during the consecutive growing seasons.

The spring barley was the forecrop for winter wheat. The Tobak wheat variety was sown annually on 20-25 September. The soil was fertilized with magnesium in the form of kieserite $\left(\mathrm{MgSO}_{4} \mathrm{H}_{2} \mathrm{O}\right)$, containing $25 \% \mathrm{MgO}$ and $50 \% \mathrm{SO}_{3}$. Kieserite was applied into the soil three weeks before wheat sowing. Foliar fertilization of wheat with $\mathrm{Mg}$ was carried out, using Epsom salt $\left(\mathrm{MgSO}_{4} \mathrm{H}_{2} \mathrm{O}\right)$ containing $16 \% \mathrm{MgO}$ and $37.5 \% \mathrm{SO}_{3}$. The amounts of the applied nutrients are shown in Table 2. The sulfur applied together with the magnesium fertilizers was balanced in the first dose of $\mathrm{N}$. It was used as a mixture of ammonium sulfate and ammonium saltpeter $\left(17.5 \% \mathrm{SO}_{3}\right)$. The first $\mathrm{N}$ dose of $80 \mathrm{~kg} \mathrm{ha}^{-1}$ was applied just before the beginning of the growing season in spring. The second dose of $50 \mathrm{~kg} \mathrm{ha}^{-1}$ was applied at $\mathrm{BBCH} 30 / 31$, and the third one of $60 \mathrm{~kg} \mathrm{ha}^{-1}$ at BBCH 45-47. Phosphorus at a rate of $30.1 \mathrm{~kg} \mathrm{P} \mathrm{ha}^{-1}$ as triple superphosphate $\left(46 \% \mathrm{P}_{2} \mathrm{O}_{5}\right)$ and $\mathrm{K}$ at a rate of $66.4 \mathrm{~kg} \mathrm{Kha}^{-1}$ as muriate of potash $(\mathrm{KCl})$ were applied together with the soil magnesium. The total area of a single plot was $30 \mathrm{~m}^{2}$ with a harvested area of $15 \mathrm{~m}^{2}$. Plant protection was conducted in accordance with the codex of good practice.

Table 2. Fertilization schedule.

\begin{tabular}{|c|c|c|c|c|}
\hline Treatment & Fertilization Schedule & $\mathrm{N}-\mathrm{P}_{2} \mathrm{O}_{5}-\mathrm{K}_{2} \mathrm{O}$ & $\begin{array}{c}\mathrm{Mg} \text {-Soil } \\
\mathrm{kg} \mathrm{ha}^{-1}\end{array}$ & Mg_Foliar \\
\hline 1.1 & NPK & $190-70-80$ & 0 & 0 \\
\hline 2.1 & $\mathrm{NPK}-\mathrm{Mg}$ foliar BBCH 30 & $190-70-80$ & 0 & 2.4 \\
\hline 2.2 & $\mathrm{NPK}-\mathrm{Mg}$ foliar BBCH 49/50 & $190-70-80$ & 0 & 4.0 \\
\hline 2.3 & $\mathrm{NPK}-\mathrm{Mg}$ foliar BBCH $30+49.50$ & $190-70-80$ & 0 & 6.4 \\
\hline 3.1 & $\mathrm{NPK}-\mathrm{Mg}$ soil & $190-70-80$ & 25 & 0 \\
\hline 3.2 & $\mathrm{NPK}-\mathrm{Mg}$ soil + foliar BBCH 30 & $190-70-80$ & 25 & 2.4 \\
\hline 3.3 & NPK-Mg soil + foliar BBCH 49/50 & $190-70-80$ & 25 & 4.0 \\
\hline 3.4 & NPK-Mg soil + foliar BBCH $30+49 / 50$ & $190-70-80$ & 25 & 6.4 \\
\hline 4.1 & NPK-Mg soil & $190-70-80$ & 50 & 0 \\
\hline 4.2 & $\mathrm{NPK}-\mathrm{Mg}$ soil + foliar BBCH 30 & $190-70-80$ & 50 & 2.4 \\
\hline 4.3 & NPK-Mg soil + foliar BBCH 49/50 & $190-70-80$ & 50 & 4.0 \\
\hline 4.4 & $\mathrm{NPK}-\mathrm{Mg}$ soil + foliar BBCH $30+49 / 50$ & $190-70-80$ & 50 & 6.4 \\
\hline
\end{tabular}




\subsection{Plant Material Sampling and Analysis}

The plant material used for dry matter determination was collected at $\mathrm{BBCH} 58, \mathrm{BBCH}$ 79 , and BBCH 89 from an area of $2.0 \mathrm{~m}^{2}$. The sampled material was then divided, depending on the wheat stage, into subsamples of leaves (LE), stems (ST), ears (EA), chaffs (CH), and grain $(\mathrm{G})$. The results are expressed on a dry weight basis.

\subsection{Calculated Parameters}

The following set of plant parameters was calculated:

1. Dry matter remobilization quota (REQ):
a. $\mathrm{REQ79}=\mathrm{TB} 58-\mathrm{TBv79}, \mathrm{t} \mathrm{ha}^{-1}$.
b. REQ79-89 = TBv79 $-\mathrm{TBv} 89, \mathrm{t} \mathrm{ha}^{-1}$.
c. $\mathrm{REQ} 89=\mathrm{TB} 58-\mathrm{TBv} 89, \mathrm{t} \mathrm{ha}^{-1}$.

2. Dry matter remobilization efficiency (ReE):
a. $\operatorname{ReE79}=\mathrm{REQ79} / \mathrm{TB} 58, \%$.
b. ReE79-89 = REQ79/TBv79, \%.
c. $\operatorname{ReE} 89=\mathrm{REQ} 89 / \mathrm{TB} 58, \%$.

3. Contribution of remobilized dry matter in the grain yield $(\operatorname{ReG})$ :
a. $\operatorname{ReG79}=\mathrm{REQ79} / \mathrm{GY} 79, \%$.
b. ReG79-89 = REQ79/ $\triangle$ GT79-89, \%.
c. $\operatorname{ReG79}=\mathrm{REQ} 89 / \mathrm{GY} 89, \%$.

4. Current photosynthesis $(\mathrm{CP})$ :
a. $\mathrm{CP79}=\mathrm{TB} 79-\mathrm{TB} 58, \mathrm{t} \mathrm{ha}^{-1}$.

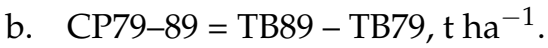
c. $\mathrm{CP} 89=\mathrm{TB} 89-\mathrm{TB} 58, \mathrm{tha}^{-1}$.

5. Efficiency of current photosynthesis (CPE):
a. CPE79/TB58, \%.
b. CPE79-89/TB79, \%.
c. CPE89/TB58, \%.

6. Contribution of current photosynthesis to the grain yield (CPG):
a. $\mathrm{CPG79}=\mathrm{CP} 79 / \mathrm{GY} 79, \%$.

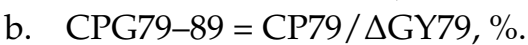
c. $\mathrm{CPG79}=\mathrm{CP} 79 / \mathrm{GY} 89, \%$.

where

TB58 - dry matter (leaves + stem + ear) yield of wheat at BBCH 58, $\mathrm{t} \mathrm{ha}^{-1} \mathrm{DW}$.

TBv79-dry matter (leaves + stem + chaffs) yield of wheat at BBCH 79, $\mathrm{t} \mathrm{ha}^{-1} \mathrm{DW}$.

GY79-dry matter yield of grain at $\mathrm{BBCH} 79, \mathrm{tha}^{-1} \mathrm{DW}$.

TB79-total dry matter (leaves + stem + chaffs + grain) yield of wheat at BBCH 79, t ha ${ }^{-1}$ DW.

TBv89-dry matter (leaves + stem + chaffs) yield of wheat at BBCH 79, $\mathrm{t} \mathrm{ha}^{-1} \mathrm{DW}$.

$\triangle G Y 89$ - dry matter yield of grain at BBCH 79-89, $\mathrm{t} \mathrm{ha}^{-1} \mathrm{DW}$.

GY89-dry matter yield of grain at BBCH 79, $\mathrm{t} \mathrm{ha}^{-1} \mathrm{DW}$.

TB89-total dry matter (leaves + stem + chaffs + grain) yield of wheat at BBCH 79, $\mathrm{t} \mathrm{ha}^{-1} \mathrm{DW}$.

\subsection{Statistical Analysis}

The collected data were subjected to an analysis of variance using STATISTICA ${ }^{\circledR} 13$ (StatSoft, Inc., Krakow, Poland 2013). The distribution of the data (normality) was checked using the Shapiro-Wilk test. The homogeneity of variance was checked by the Bartlett test. Means were separated by honest significant difference (HSD) using Tukey's method, 
when the $F$-test indicated significant factorial effects at the level of $p<0.05$. To determine the wheat grain yield, stepwise regression was used to define the optimal set of wheat components. In the computational procedure, a consecutive variable was removed from the multiple regressions in a step-by-step manner. The best regression model was chosen based on the highest F-value for the model and the significance of all variables.

\section{Results}

\subsection{Grain Yield and Yield Structure}

The wheat grain yield significantly resulted from the interaction of magnesium fertilization systems $(\mathrm{MgFs})$, regardless of the course of the weather in the subsequent years of the study (Table 3). The interaction between magnesium fertilization systems (Mg application) was very specific (Figure 2). Soil-applied $\mathrm{Mg}$, irrespective of its dose, resulted in a significant increase in the yield, reaching 5-6\% $\left(+0.5 \mathrm{tha}^{-1}\right)$ compared to the Mg-control plot, i.e., fertilized only with NPK. The net effect of magnesium foliar fertilization (Mg-FF) was the highest on the $\mathrm{Mg}$-control plot. On this particular plot, due to foliar application of $\mathrm{Mg}$, the grain yield increased by $6-7 \%$ compared to the $\mathrm{Mg}$-absolute control $\left(+0.7 \mathrm{tha}^{-1}\right)$. The interaction of the soil $\mathrm{Mg}$ application and the double-stage $\mathrm{Mg}$-FFs resulted in a further yield increase. The significant effect of this system of $\mathrm{Mg}$ fertilization was the strongest on the plot fertilized with both $50 \mathrm{~kg} \mathrm{Mg} \mathrm{ha}{ }^{-1}$ and $\mathrm{Mg}$-FF at $\mathrm{BBCH} 30$ and repeated at $\mathrm{BBCH}$ 49/50. The relative increase in the yield compared to the $\mathrm{Mg}$-absolute control was $10 \%$ $\left(0.92 \mathrm{tha}^{-1}\right)$.

Table 3. Statistical evaluation of factors affecting in-season yields of winter wheat and yield basic parameters.

\begin{tabular}{|c|c|c|c|c|c|c|}
\hline Factor & $\begin{array}{l}\text { Level of } \\
\text { Factor }\end{array}$ & $\begin{array}{c}\mathrm{GY}^{2} \\
\text { t ha } \\
\end{array}$ & $\begin{array}{c}\text { ED } \\
\text { No. } \mathrm{m}^{-2}\end{array}$ & $\begin{array}{c}\text { GR } \\
\text { No. } \text { ear }^{-1}\end{array}$ & $\begin{array}{c}\text { GD } \\
\text { No. } \mathbf{m}^{-2}\end{array}$ & $\begin{array}{c}\text { TGW } \\
\mathrm{g}\end{array}$ \\
\hline $\begin{array}{l}\text { Year } \\
\text { (Y) }\end{array}$ & $\begin{array}{l}2013 \\
2014 \\
2015\end{array}$ & $\begin{array}{c}8.459 \mathrm{c} \\
10.934 \mathrm{a} \\
9.689 \mathrm{~b} \\
* * *\end{array}$ & $\begin{array}{c}496.6 \mathrm{c} \\
639.9 \mathrm{~b} \\
684.2 \mathrm{a} \\
* * *\end{array}$ & $\begin{array}{c}36.4 \mathrm{~b} \\
43.2 \mathrm{a} \\
31.5 \mathrm{c} \\
* * *\end{array}$ & $\begin{array}{c}18,073 \mathrm{c} \\
27,668 \mathrm{a} \\
21,554 \mathrm{~b} \\
* * *\end{array}$ & $\begin{array}{l}51.4 \mathrm{a} \\
45.8 \mathrm{~b} \\
45.9 \mathrm{~b}\end{array}$ \\
\hline $\begin{array}{c}\text { Mg soil } \\
(\mathrm{MgS}) \\
\mathrm{kg} \mathrm{ha}^{-1}\end{array}$ & $\begin{array}{c}0 \\
25 \\
50\end{array}$ & $\begin{array}{c}9.536 \mathrm{~b} \\
9.716 \mathrm{a} \\
9.830 \mathrm{a} \\
* * *\end{array}$ & $\begin{array}{c}606.7 \mathrm{ab} \\
595.9 \mathrm{~b} \\
618.1 \mathrm{a} \\
* * *\end{array}$ & $\begin{array}{c}35.8 \mathrm{~b} \\
37.6 \mathrm{a} \\
37.8 \mathrm{a} \\
* *\end{array}$ & $\begin{array}{c}21,676 \mathrm{c} \\
22,438 \mathrm{ab} \\
23,181 \mathrm{a} \\
\text { n.s. }\end{array}$ & $\begin{array}{l}47.7 \\
47.9 \\
47.5 \\
\text { n.s. }\end{array}$ \\
\hline $\begin{array}{c}\mathrm{Mg} \text { foliar } \\
\\
(\mathrm{MgF}) \\
\text { terms }\end{array}$ & $\begin{array}{c}0 \\
\text { I } \\
\text { II } \\
\text { I + II }\end{array}$ & $\begin{array}{c}9.428 \mathrm{~b} \\
9.793 \mathrm{a} \\
9.713 \mathrm{a} \\
9.842 \mathrm{a} \\
* * *\end{array}$ & $\begin{array}{c}595.3 \mathrm{~b} \\
624.5 \mathrm{a} \\
597.3 \mathrm{~b} \\
610.4 \mathrm{ab} \\
*\end{array}$ & $\begin{array}{c}36.1 \mathrm{c} \\
37.2 \mathrm{~b} \\
36.9 \mathrm{bc} \\
38.1 \mathrm{a} \\
* * *\end{array}$ & $\begin{array}{c}21,374 \mathrm{c} \\
23,094 \mathrm{ab} \\
21,976 \mathrm{bc} \\
23,283 \mathrm{a} \\
* * *\end{array}$ & $\begin{array}{c}47.2 \mathrm{~b} \\
47.4 \mathrm{ab} \\
48.1 \mathrm{a} \\
48.1 \mathrm{a} \\
* *\end{array}$ \\
\hline \multicolumn{7}{|c|}{ Source of variation for interactions } \\
\hline $\begin{array}{r}\mathrm{Y} \\
\mathrm{Y} \\
\mathrm{Mg} \\
\mathrm{Y} \times \mathrm{I}\end{array}$ & $\mathrm{MgF}$ & $\begin{array}{c}\text { n.s. } \\
\text { n.s. } \\
* \\
\text { n.s. }\end{array}$ & $\begin{array}{l}* * \\
* * \\
\text { n.s. } \\
* *\end{array}$ & $\begin{array}{l}* * * \\
* * * \\
\text { n.s. } \\
\text { n.s. }\end{array}$ & $\begin{array}{c}\text { n.s. } \\
\text { n.s. } \\
* \\
\text { n.s. }\end{array}$ & $\begin{array}{l}\text { n.s. } \\
\text { n.s. } \\
\text { n.s. } \\
\text { n.s. }\end{array}$ \\
\hline
\end{tabular}

a, b, c similar letters mean a lack of significant differences using Tukey's test; ${ }^{* * *}, * *$, and ${ }^{*}$ indicate significant differences at $p<0.001, p<0.01$, and $p<0.05$, respectively; n.s. = not significant. Legend: ${ }^{1}$ I-BBCH 30; II$\mathrm{BBCH} 49 / 50$; $\mathrm{GY}^{2}$ —grain yield (86\% DW); ED—ears' density; GR—grain per ear; GD—grain density per $\mathrm{m}^{2}$; TGW-thousand grain weight. 


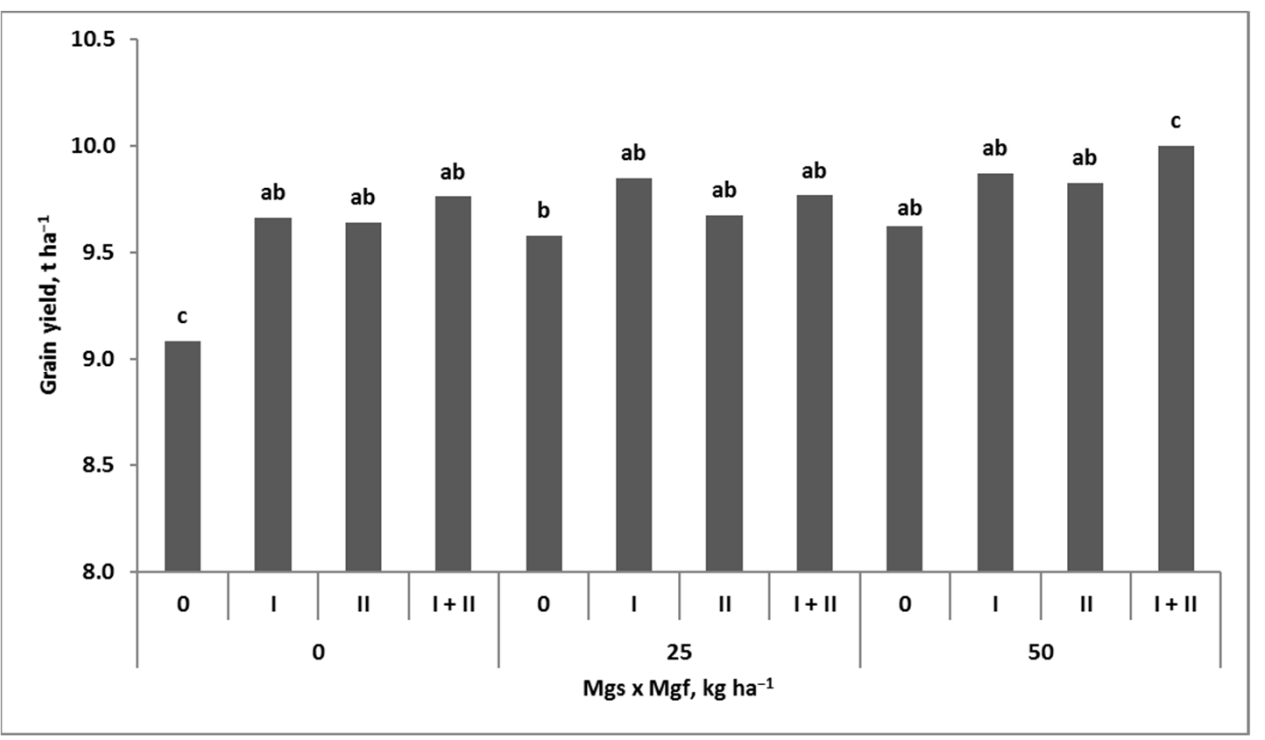

Figure 2. Effect of magnesium fertilization systems on the grain yield of wheat. a, b, c similar letters mean a lack of significant differences using Tukey's test; Legend: Mgs, Mgf—soil and foliar Mg fertilization system, respectively.

Out of the four examined yield components, the only thousand grain weight (TGW) did not respond to the interaction of experimental factors and years (Table 3). A significant increase in TGW resulted from Mg-FF at BBCH 49/50 or its two-stage application. A significantly higher TGW was recorded in 2013 compared to other years of the study. This yield component was negatively correlated with the grain yield (Table A1). It also showed negative relationships with other yield components. Ears' density (ED) was the only yield component that significantly responded to the interaction of years and magnesium fertilization systems (Mg-FSs), but without a dominant impact on the grain yield (Table A1). The number of grain per ear (GR) affected the grain yield, but was not the component, which can be used for the grain yield diagnosis. Grain density (GD), which responded to the interaction of both magnesium fertilization systems, was revealed as the best indicator of the grain yield. The dependence obtained is presented below:

$$
\mathrm{GY}=0.0138 \mathrm{GD}^{2}+0.879 \mathrm{GD}-2.828 \text { for } n=36, \mathrm{R}^{2}=0.95, \text { and } p \leq 0.01
$$

The obtained equation clearly shows that each unit increase in GD to $31.84 \times 1000$ grain per $\mathrm{m}^{2}$ resulted in a progressive increase in the yield to a maximum of $11.169 \mathrm{t} \mathrm{ha}^{-1}$.

\subsection{Wheat Biomass Structure during the Grain-Filling Period}

The structure of wheat biomass was investigated in three well-defined stages of this crop growth, i.e., the end of heading (BBCH 58), the end of the milk stage (BBCH 79), and at maturity ( $\mathrm{BBCH} 89)$ [37]. Based on the stepwise regression analysis, it was found that the leaf biomass at $\mathrm{BBCH} 58$ was the best single grain yield indicator from among 14 examined biomass components (Table A1). The regression model obtained is as follows:

$$
\mathrm{GY}=1.706 \mathrm{LE} 58+5.046 \text { for } n=36, \mathrm{R}^{2}=0.82 \text {, and } p \leq 0.01
$$

The year was, in fact, the dominant factor that significantly affected the variability in the leaf biomass at BBCH 58 (Table 4, Figure 3). The highest biomass, averaged for experimental treatments, was recorded in 2014. It was 78\% and 18\% higher than in 2013 and 2015 . For comparison, the difference in the grain yield was only $29 \%$ and $13 \%$, respectively. The effect of Mg-FSs on this wheat trait was clear, but, at the same time, very diverse in the subsequent years of study. Every year, the most significant response of leaf biomass to $\mathrm{Mg}$ application was found on the plot fertilized with $25 \mathrm{~kg} \mathrm{Mg} \mathrm{ha}^{-1}$. In 2013, the 
highest leaf biomass was recorded on the plot with $\mathrm{Mg}$-FF at the $\mathrm{BBCH} 49 / 50$ stage, but the differences between treatments were low. In the other two years, the maximum biomass was recorded on a plot with a two-stage $\mathrm{Mg}-\mathrm{FF}$, i.e., at $\mathrm{BBCH} 30$, and repeated at $\mathrm{BBCH}$ 49/50. A significant response of leaf biomass response to $\mathrm{Mg}$-FF was also recorded on the Mg-soil control in 2015. On the other hand, Mg-FF on the main plot fertilized with $50 \mathrm{~kg}$ $\mathrm{Mg} \mathrm{ha}^{-1}$ caused a reduction in the leaf biomass compared to the Mg-soil control.

In-season grain yield of wheat, as determined at the $\mathrm{BBCH} 79$ stage, significantly responded to the interaction of both experimental factors and years (Table 4, Figure 4). The weather course was the main factor affecting the yield. The highest yield recorded in 2015 was $11.5 \%$ higher compared to 2014 and $27.3 \%$ compared to 2013. The impact of Mg application was very different in the studied years. In 2013, Mg-FSs, in general, led to yield reduction. This dominant, but negative, trend in response to soil-applied $\mathrm{Mg}$ was weakened by $\mathrm{Mg}$-FF at BBCH 30. In 2014, the significant grain yield increase in response to $\mathrm{Mg}$ application was recorded only on the $\mathrm{Mg}$-soil control. The interactional effect of both Mg-FSs was revealed on the plot treated with $25 \mathrm{~kg} \mathrm{Mg} \mathrm{ha}^{-1}$, showing a slight increase in grain yield. In 2015, the interactional effect of Mg-FSs was recorded on the plot treated with $50 \mathrm{~kg} \mathrm{Mg} \mathrm{ha}^{-1}$ and $\mathrm{Mg}$-FF at BBCH 49/50. In other main plots, Mg applied to the wheat foliage resulted in a reduction in the wheat grain yield, compared to the corresponding Mg-controls.

The grain yield in the $\mathrm{BBCH} 79$ stage of wheat development showed significant relationships with the biomass of all parts of wheat at $\mathrm{BBCH}$ 58. Stepwise regression analysis showed that the effect of chaff biomass on the yield can only be assessed together with the leaf biomass. The yield wheat grain at $\mathrm{BBCH} 79$ was positively correlated with the leaf biomass, and at the same time was negatively correlated with the chaff biomass:

$$
\text { GY79 }=6.148+0.88 \text { LE5 } 8-0.305 \text { CH79 for } n=36, \mathrm{R}^{2}=0.62 \text {, and } p \leq 0.01
$$

Leaf biomass was highly stable over the period, ranging from $\mathrm{BBCH} 58$ to $\mathrm{BBCH} 79$ (Table 4). In this period of wheat development, a slight increase in the leaf biomass in 2013 and a significant decrease in the remaining years of study were noted. The observed decrease was most evident in 2014 on the plot with $25 \mathrm{~kg} \mathrm{Mg} \mathrm{ha}^{-1}$. Ear biomass showed a deep decrease during this period, but only in 2014 and 2015, amounting to 0.36 and $1.66 \mathrm{t} \mathrm{ha}^{-1}$. Stem biomass in this particular period increased significantly in 2013, while it decreased substantially in the other two years. This decrease was particularly large in 2014, when it amounted to $1.68 \mathrm{t} \mathrm{ha}^{-1}$. The wheat GY79 was positively and significantly correlated with $\mathrm{ED}\left(+0.83^{* * *}\right)$, but at the same time negatively with TGW $\left(-0.73^{* * *}\right)$. The same pattern of relationships was observed for biomass in all wheat organs at $\mathrm{BBCH} 58$ and leaf biomass at $\mathrm{BBCH} 79$, but not for stem and chaff biomass at the latter stage (Table A1).

The grain yield increased until the wheat was mature. The recorded increase in the yield in the maturation phase of wheat growth, defined as dGY89, was significantly dependent on the interaction of all factors (Table 4). The effect of Mg-FSs on dGY89 was most pronounced in 2014 (Figure 5). In this particular year, dGY89, averaged over the examined Mg-FSs, was two-, and almost six-fold higher than in 2013 and 2015, respectively. In 2014, the effect of soil-applied Mg was progressive, but slight. The strongest increase in dGY79 was recorded on the Mg-control and the main plot fertilized with $25 \mathrm{~kg} \mathrm{Mg} \mathrm{ha}^{-1}$, and simultaneously treated with $\mathrm{Mg}$ in a double $\mathrm{Mg}$-FF system. 


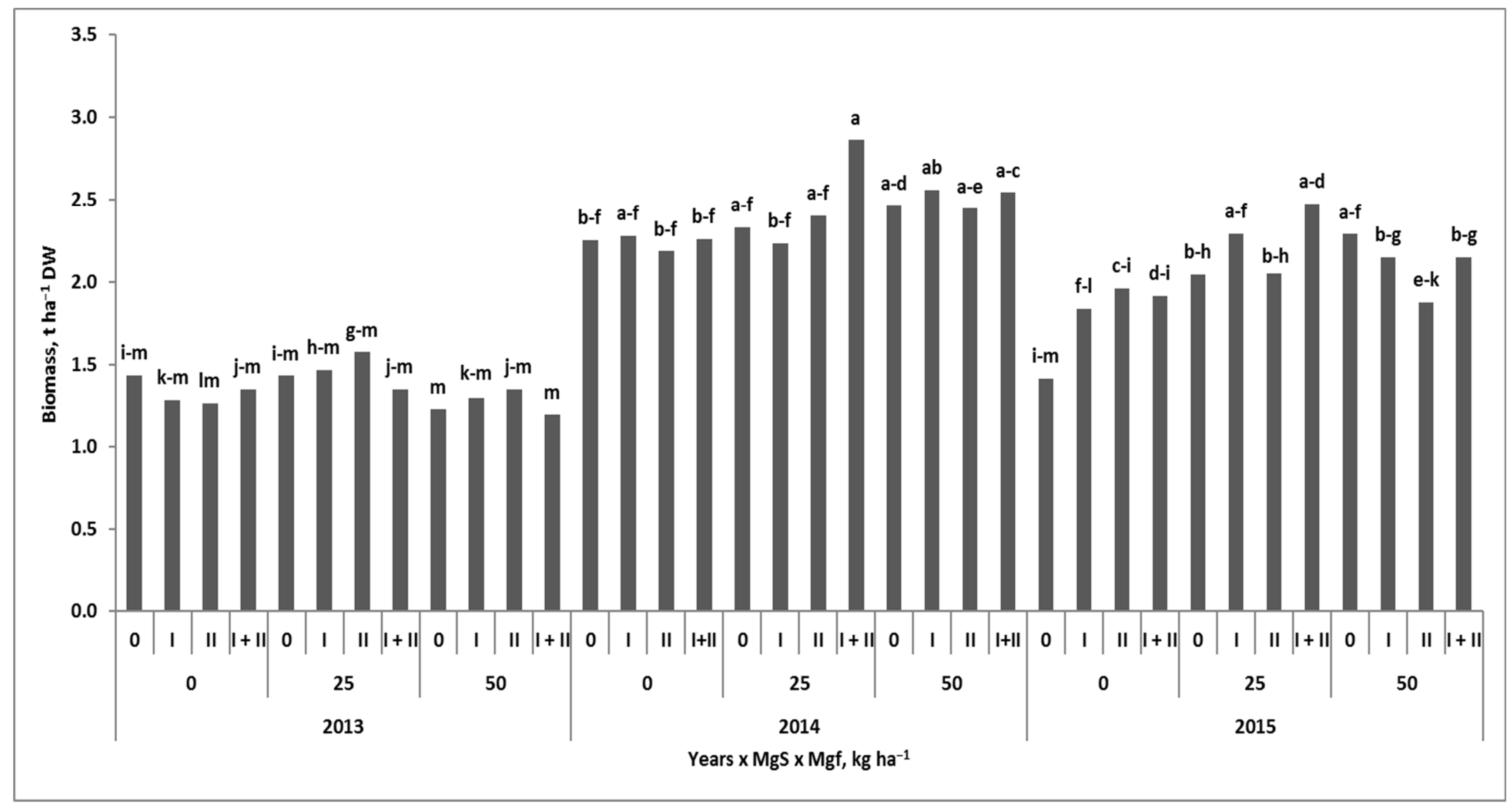

Figure 3. Effect of magnesium fertilization systems on the background of years on the leaf biomass of winter wheat at the BBCH 58 stage. Similar letters mean a lack of significant differences using Tukey's test. Legend: Mgs, Mgf—soil and foliar Mg fertilization systems, respectively; I—BBCH 30; II—BBCH 49/50. 
Table 4. Statistical evaluation of factors affecting wheat biomass at critical stages of the grain-filling period.

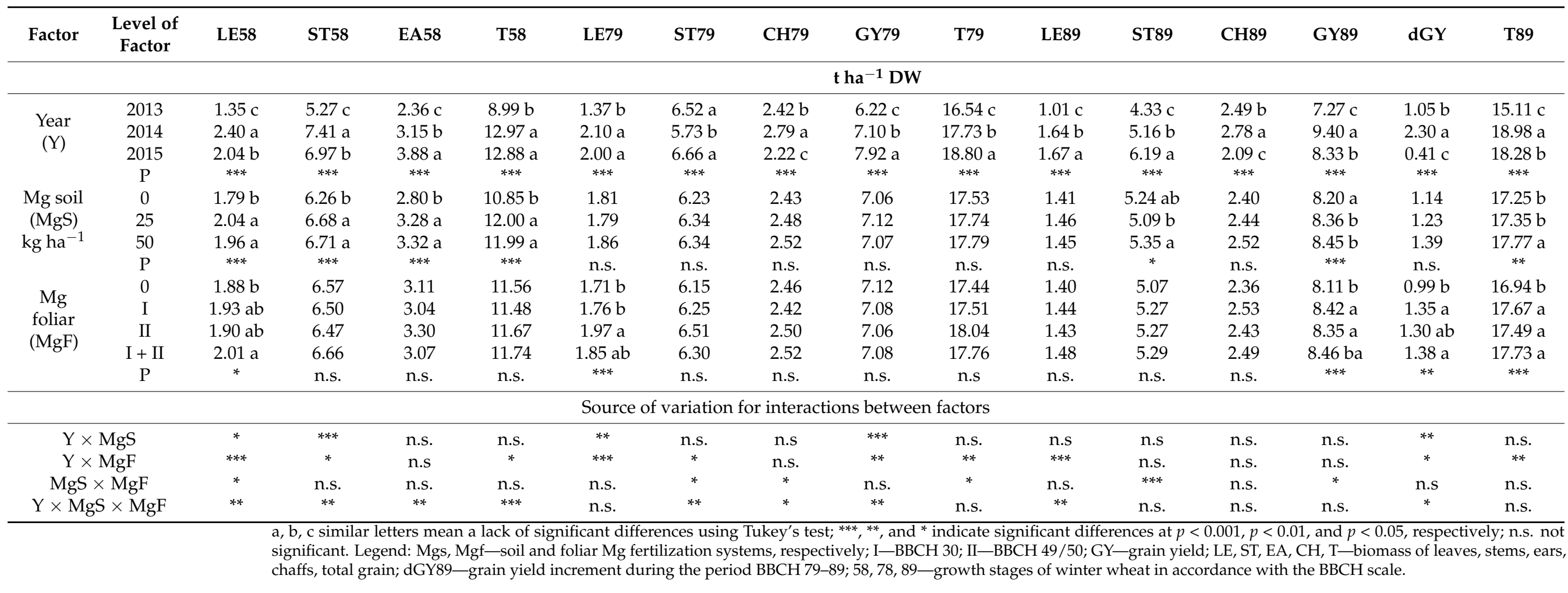




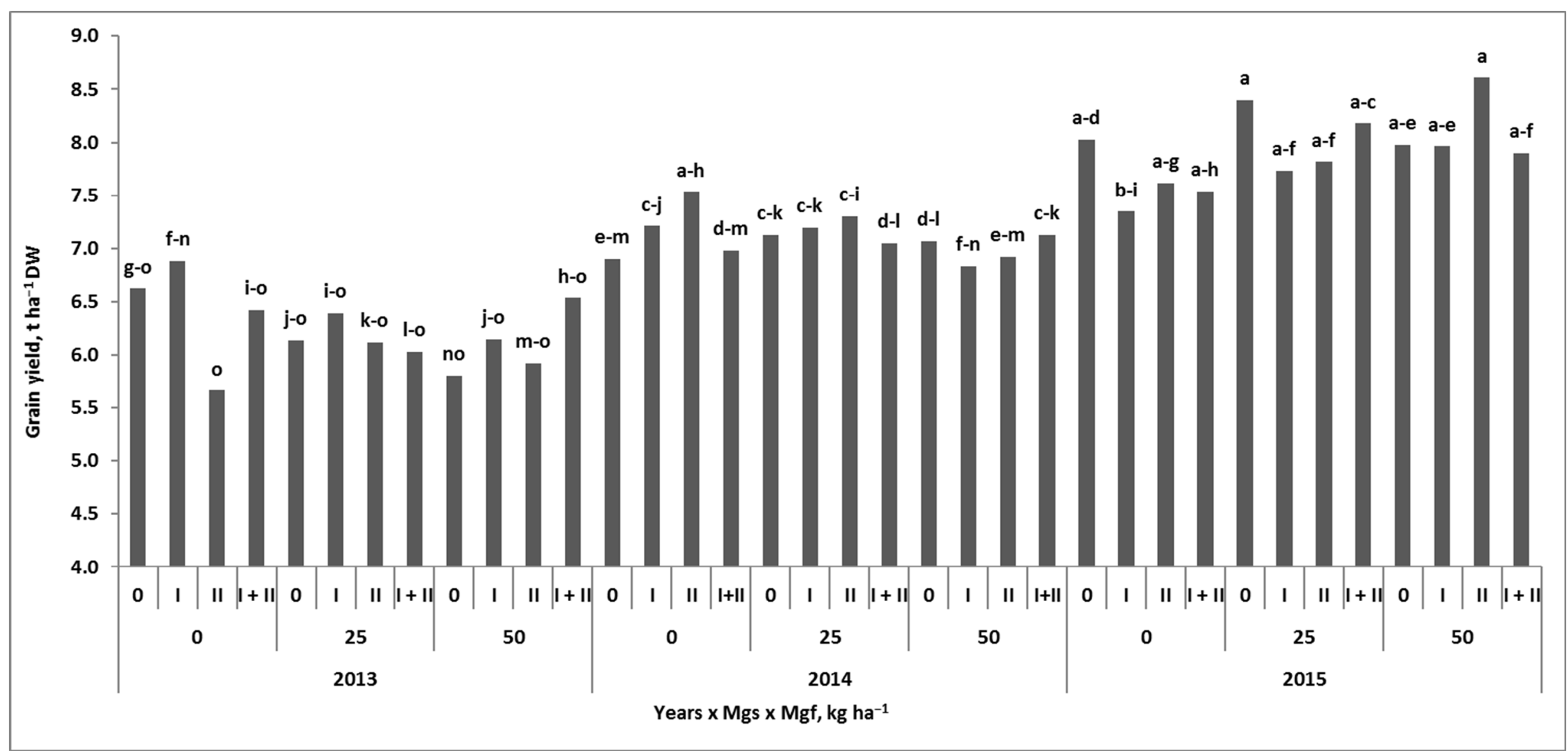

Figure 4. Effect of magnesium fertilization systems on the background of years on the temporary grain yield of winter wheat at the BBCH 79 stage. Similar letters mean a lack of significant differences using Tukey's test. Legend: Mgs, Mgf—soil and foliar Mg fertilization systems, respectively; I-BBCH 30; II—BBCH 49/50. 


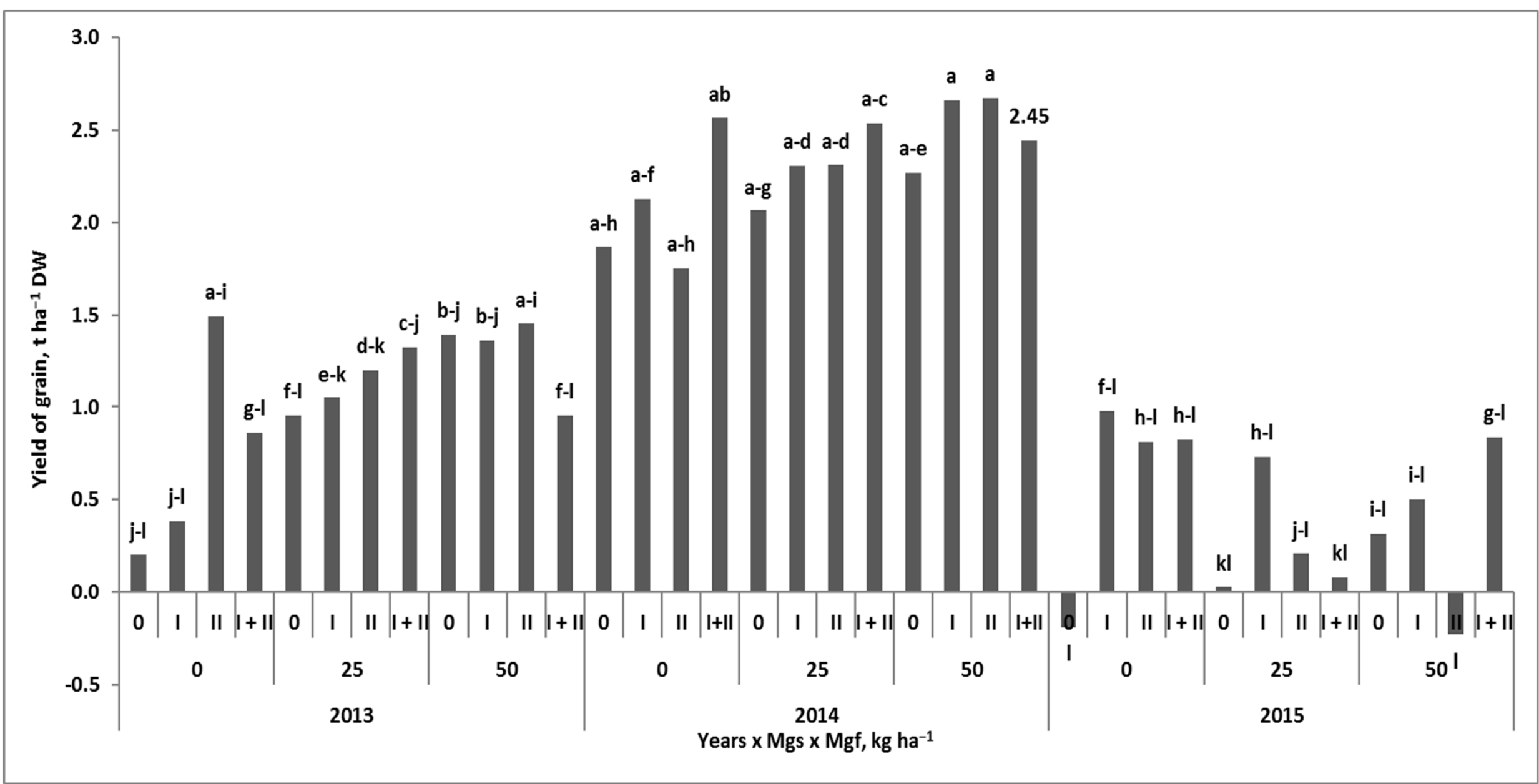

Figure 5. Effect of magnesium fertilization systems on the background of years on the increment of the grain yield of winter wheat in the maturation phase. Similar letters mean a lack of significant differences using Tukey's test. Legend: Mgs, Mgf—soil and foliar Mg fertilization systems, respectively; I-BBCH 30; II—BBCH $49 / 50$. 
On the plot with $50 \mathrm{~kg} \mathrm{Mg} \mathrm{ha}{ }^{-1}$, the best $\mathrm{Mg}$-FF effect was achieved at BBCH 30 or 49/50. In 2013, the effect of the soil-applied Mg increased along its dose. The actual increase in the yield on the Mg-control plot was highest on the Mg-FF-BBCH 49/50 plot. The interactional effect of both Mg-FSs was the best on the plot with $25 \mathrm{~kg} \mathrm{Mg} \mathrm{ha}^{-1}$. The highest dGY89 was recorded on the Mg-FF at BBCH 49/50. No effect of $\mathrm{Mg}$-FF was observed on the plot treated with $50 \mathrm{~kg} \mathrm{Mg} \mathrm{ha}^{-1}$. In 2015, the effect of the soil-applied $\mathrm{Mg}$ on dGY89 was low. The best effect of Mg-FF was observed, regardless on the stage of its application, on the Mg-soil control plot. The positive effect of $\mathrm{Mg}-\mathrm{FF}$ on the plots with soil-applied $\mathrm{Mg}$ was very diverse, depending on the stage of application. It should be emphasized that the number of grains per ear (GE) and grain density (GD) had a positive effect on the increase in the wheat grain yield during the maturation phase. The first component was decisive, determining the value of dGY89:

$$
\mathrm{dGY} 89=0.154 \mathrm{GE}-4.436 \text { for } n=36, \mathrm{R}^{2}=0.81, \text { and } p \leq 0.1
$$

\subsection{Indices of Dry Matter Management by Wheat during the Grain-Filling Period}

The yield of wheat grain depends on two sources of assimilates. The first concerns the amount of dry matter remobilized from the vegetative organs of wheat during its post-flowering growth. The second source is the current photosynthesis of physiologically active parts of the plant [38]. The yield-forming role of both sources was assessed on the basis of two time intervals of wheat growth. In the first calculation procedure, the studied period covered the entire post-flowering period, i.e., from $\mathrm{BBCH} 58$ to $\mathrm{BBCH} 89$. In the second procedure, the intermediate phases of wheat grain yield development were studied. The period from $\mathrm{BBCH} 58$ to $\mathrm{BBCH} 79$ included the phases responsible for grain expansion. The second, from BBCH 79 to $\mathrm{BBCH} 89$, covered the grain maturation phase [37].

The basic indicator of dry matter management by wheat throughout the grain-filling period (GFP) is the amount of dry matter remobilized (REQ89) from the vegetative parts of the plant [37]. Positive values of this index indicate a decrease, and negative-an increase in dry weight in the assessed period (Table 5). The conducted study showed that the weather conditions during the growing season were the dominant factor, influencing the value of REQ89 (Figure 6). The greatest impact of Mg-FSs on this wheat trait was found in 2014. This index was 2.8-fold, and 17\% higher than in 2013 and 2015. In 2014, REQ89 gradually increased with the $\mathrm{Mg}$ soil-applied dose. In comparison to the $\mathrm{Mg}$-control, the increase in REQ89 on the plot with $25 \mathrm{~kg} \mathrm{ha}^{-1}$ was $36.4 \%$, and $72.7 \%$ on the plot with $50 \mathrm{Mg} \mathrm{kg} \mathrm{ha}{ }^{-1}$. The effect of Mg-FF was usually negative, except for the two-stage $\mathrm{Mg}$-FF application, which increased REQ89 from $4.5 \mathrm{t} \mathrm{ha}^{-1}$ to $5.3 \mathrm{t} \mathrm{ha}^{-1}$. In 2015, the effect of the soil-applied Mg showed the same patterns as in 2014. The REQ response to the first $\mathrm{Mg}$ dose was 4.6-fold compared to the Mg-soil control. Its value increased by another $30 \%$ in response to the second $\mathrm{Mg}$ dose. The positive effect of $\mathrm{Mg}-\mathrm{FF}$ turned out to be the best on the Mg-soil control. Plants treated with $\mathrm{Mg}$ at BBCH 30 increased 4-fold REQ89 compared to the absolute Mg-control. As in 2014, the interaction of the highest soil $\mathrm{Mg}$ dose with Mg-FF resulted in a reduction in REQ89. In 2013, the effect of the soil-applied Mg was low, decreasing significantly with the increase of its dose. The best interaction of the Mg-FSs was found on the plot with $25 \mathrm{~kg} \mathrm{Mg} \mathrm{ha}^{-1}$ and Mg-FF at BBCH 49/50.

Despite the high values of REQ89, the efficiency of dry matter remobilization (ReE89) was low, reaching only $11.8 \%$ in $2013,25.4 \%$ in 2014 , and $21.9 \%$ in 2015 . The contribution of the remobilized dry matter in the grain yield (ReG89) was proportionally higher. In 2014 and 2015, it exceeded 35\%. The values of all these indicators significantly depended on the total wheat biomass at BBCH 58 (Table A2). This relationship is shown below for REQ89:

$$
\text { REQ89 }=0.605 T 58-4.529 \text { for } n=36, \mathrm{R}^{2}=0.79 \text { and } p \leq 0.01
$$


Table 5. Indices of winter wheat biomass partitioning during the grain-filling period.

\begin{tabular}{|c|c|c|c|c|c|c|c|c|c|}
\hline Factor & $\begin{array}{c}\text { Level } \\
\text { of Factor }\end{array}$ & Tv79 & $\begin{array}{c}\text { Tv89 } \\
\text { t ha }\end{array}$ & REQ89 & RE89 & $\begin{array}{ll} & \text { ReG89 } \\
\% & \end{array}$ & $\begin{array}{c}\text { CP89 } \\
\text { t ha }\end{array}$ & СРС89 & CPG89 \\
\hline \multirow{4}{*}{$\begin{array}{l}\text { Year } \\
(Y)\end{array}$} & 2013 & $10.3 \mathrm{~b}$ & $7.8 \mathrm{c}$ & $1.2 \mathrm{~b}$ & $11.8 \mathrm{~b}$ & $15.9 \mathrm{~b}$ & $6.1 \mathrm{a}$ & $70.1 \mathrm{a}$ & $84.1 \mathrm{a}$ \\
\hline & 2014 & $10.6 \mathrm{ab}$ & $9.6 \mathrm{~b}$ & $3.4 \mathrm{a}$ & $25.4 \mathrm{a}$ & $36.1 \mathrm{a}$ & $6.0 \mathrm{ab}$ & $47.9 \mathrm{~b}$ & $63.9 \mathrm{~b}$ \\
\hline & 2015 & $10.9 \mathrm{a}$ & $9.9 \mathrm{a}$ & $2.9 \mathrm{a}$ & $21.9 \mathrm{a}$ & $35.3 \mathrm{a}$ & $5.4 \mathrm{~b}$ & $43,4 \mathrm{~b}$ & $64.7 \mathrm{~b}$ \\
\hline & $\mathrm{P}$ & $*$ & $* * *$ & $* * *$ & $* * *$ & $* * *$ & $*$ & $* * *$ & $* * *$ \\
\hline \multirow{4}{*}{$\begin{array}{l}\text { Mg soil } \\
(\mathrm{MgS}) \\
\mathrm{kg} \mathrm{ha}^{-1}\end{array}$} & 0 & 10.5 & 9.1 & $1.8 \mathrm{~b}$ & $15.2 \mathrm{~b}$ & $21.5 \mathrm{~b}$ & $6.4 \mathrm{a}$ & $61.7 \mathrm{a}$ & $78.5 \mathrm{a}$ \\
\hline & 25 & 10.6 & 9.0 & $3.0 \mathrm{a}$ & $23.3 \mathrm{a}$ & $35.2 \mathrm{a}$ & $5.4 \mathrm{~b}$ & $48.1 \mathrm{~b}$ & $64.8 \mathrm{~b}$ \\
\hline & 50 & 10.7 & 9.3 & $2.7 \mathrm{a}$ & $20.6 \mathrm{a}$ & $30.6 \mathrm{a}$ & $5.8 \mathrm{~b}$ & $51.6 \mathrm{~b}$ & $69.4 \mathrm{~b}$ \\
\hline & $\mathrm{P}$ & ns & ns & $* * *$ & $* * *$ & $* * *$ & $* * *$ & $* * *$ & $* * *$ \\
\hline \multirow{5}{*}{$\begin{array}{l}\mathrm{Mg} \text { foliar }^{1} \\
\text { (MgF) }\end{array}$} & 0 & $10.3 \mathrm{~b}$ & $8.8 \mathrm{~b}$ & 2.7 & 20.7 & 31.9 & 5.4 & 51.7 & 68.1 \\
\hline & I & $10.4 \mathrm{ab}$ & $9.2 \mathrm{a}$ & 2.2 & 17.6 & 25.9 & 6.2 & 57.5 & 74.1 \\
\hline & II & $11.0 \mathrm{a}$ & $9.1 \mathrm{a}$ & 2.5 & 21.1 & 30.2 & 5.8 & 51.5 & 69.8 \\
\hline & $\mathrm{I}+\mathrm{II}$ & $10.7 \mathrm{ab}$ & $9.3 \mathrm{a}$ & 2.5 & 19.3 & 28.4 & 6.0 & 54.7 & 71.6 \\
\hline & $\mathrm{P}$ & $*$ & $*$ & ns & ns & ns & ns & ns & ns \\
\hline
\end{tabular}

Source of variation for interactions between factors

\begin{tabular}{|c|c|c|c|c|c|c|c|c|}
\hline $\mathrm{Y} \times \mathrm{MgS}$ & ns & ns & ns & ns & ns & ns & ns & ns \\
\hline $\mathrm{Y} \times \mathrm{MgF}$ & * & $* *$ & $* *$ & $* *$ & $* *$ & $* *$ & $* *$ & $* *$ \\
\hline $\mathrm{MgS} \times \mathrm{MgF}$ & * & ns & ns & $\mathrm{ns}$ & ns & ns & ns & ns \\
\hline $\mathrm{Y} \times \mathrm{MgS} \times \mathrm{MgF}$ & ns & ns & $* *$ & $* *$ & $* *$ & * & $* *$ & $* *$ \\
\hline
\end{tabular}

a, b, c similar letters mean a lack of significant differences using Tukey's test; ${ }^{* * *},{ }^{* *}$, and ${ }^{*}$ indicate significant differences at $p<0.001, p<0.01$, and $p<0.05$, respectively; ns-nonsignificant. Legend: Mgs, Mgf-soil and foliar Mg fertilization systems, respectively ${ }^{1} \mathrm{I}$ - BBCH 30; II-BBCH 49/50; Tv79, Tv89-total biomass of wheat vegetative organs; REQ — remobilization quota; RE-remobilization efficiency of REQ; ReG—contribution of REQ in the grain yield; $\mathrm{CP}$-current photosynthesis; $\mathrm{CPE}$ - efficiency of $\mathrm{CP} ; \mathrm{CPG}$-contribution of $\mathrm{CP}$ in the grain yield; 79, 89-growth stages of winter wheat in accordance with the $\mathrm{BBCH}$ scale.

This index and its derivatives showed significant relationships with both GY79 and GY89. In both cases, these relationships were poor. The regression models obtained are as follows:

$$
\begin{gathered}
\text { GY89 }=-0.075 \text { REQ } 89^{2}+0.64 \text { REQ89 }+6.095 \text { for } n=36, \mathrm{R}^{2}=0.25 \text { and } p \leq 0.05 \\
\text { GY89 }=0.417 \text { REQ89 }+7.3 \text { for } n=36, \mathrm{R}^{2}=0.43 \text { and } p \leq 0.01
\end{gathered}
$$

The current photosynthesis $(\mathrm{CP})$ showed much less sensitivity to years and Mg-FSs than REQ89 (Table 5). CP values were almost the same in the first two years of the study, averaging around $6.0 \mathrm{t} \mathrm{ha}^{-1}$. In 2015, the value of this index was $10 \%$ lower. In 2013 and 2014, the highest $\mathrm{CP}$ was recorded on the $\mathrm{Mg}$-soil control plot, provided that $\mathrm{Mg}$-FF was carried out at the BBCH 30 stage (Figure 7). The obtained values were $27.5 \%$ and $45.5 \%$ higher in comparison to the absolute Mg-control. In 2015, the increased dose of the soil-applied Mg resulted in a significant decrease in $\mathrm{CP}$. The positive and significant effect of Mg-FF was noted only on the plot fertilized with $50 \mathrm{~kg} \mathrm{Mg} \mathrm{ha}^{-1}$. The efficiency of the current photosynthesis (CPE) was the highest in 2013, exceeding $70 \%$. In the remaining years, it ranged from $40 \%$ to $50 \%$. The soil-applied Mg caused a significant decrease the index value. No significant response of $\mathrm{CPE}$ to $\mathrm{Mg}$-FF was found. The contribution of both assimilate sources in the grain yield (CPG) was very variable, ranging from $65 \%$ in 2014 and 2015 to $84 \%$ in 2013 . The values of the index decreased significantly in response to $\mathrm{Mg}$-FF. 


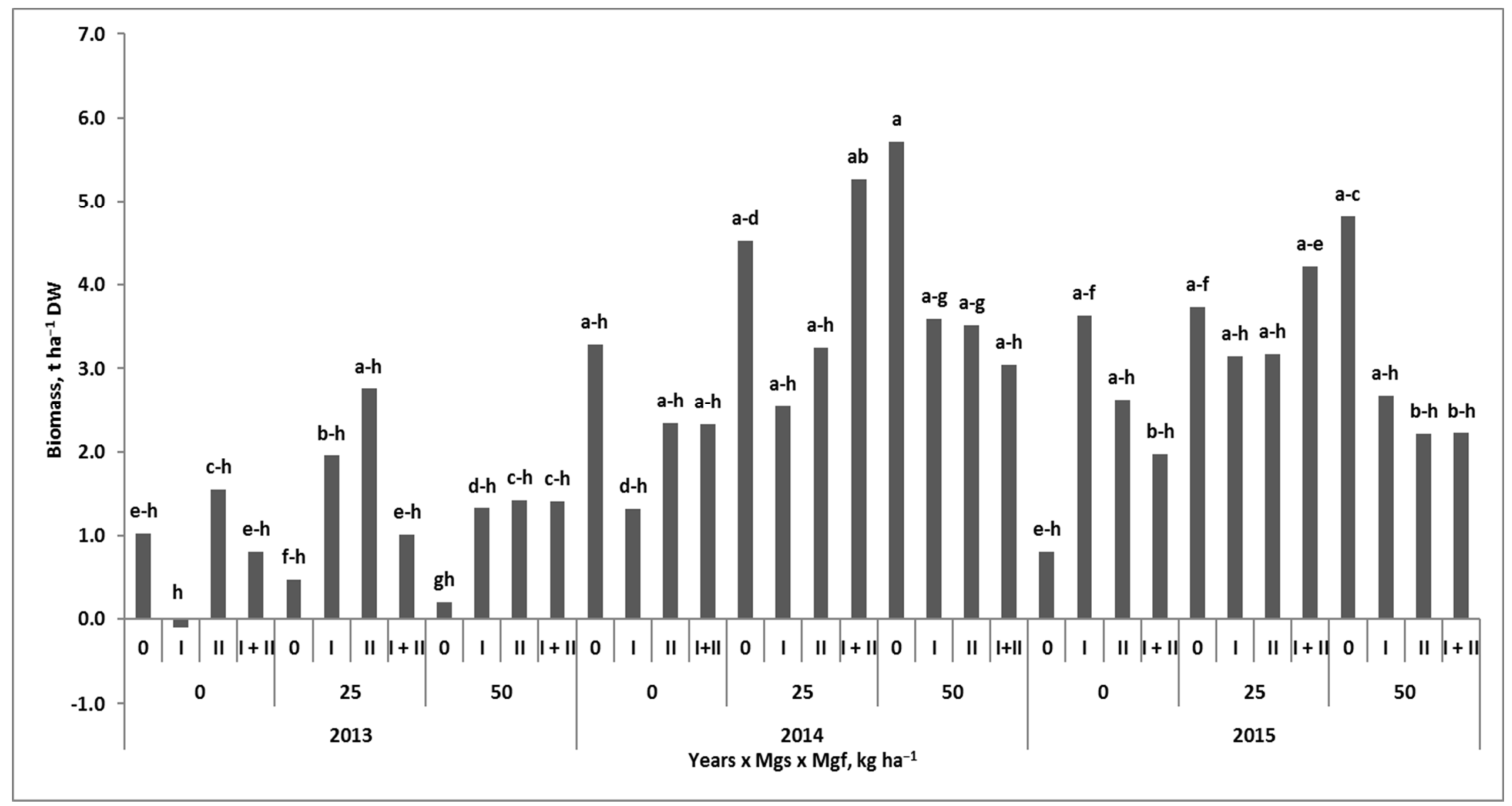

Figure 6. Effect of magnesium fertilization systems on the background of years on the remobilized dry matter of winter wheat in the grain-filling period. Similar letters mean a lack of significant differences using Tukey's test. Legend: Mgs, Mgf—soil and foliar Mg fertilization systems, respectively; $\mathrm{I}-\mathrm{BBCH}$ 30; II—BBCH $49 / 50$. 


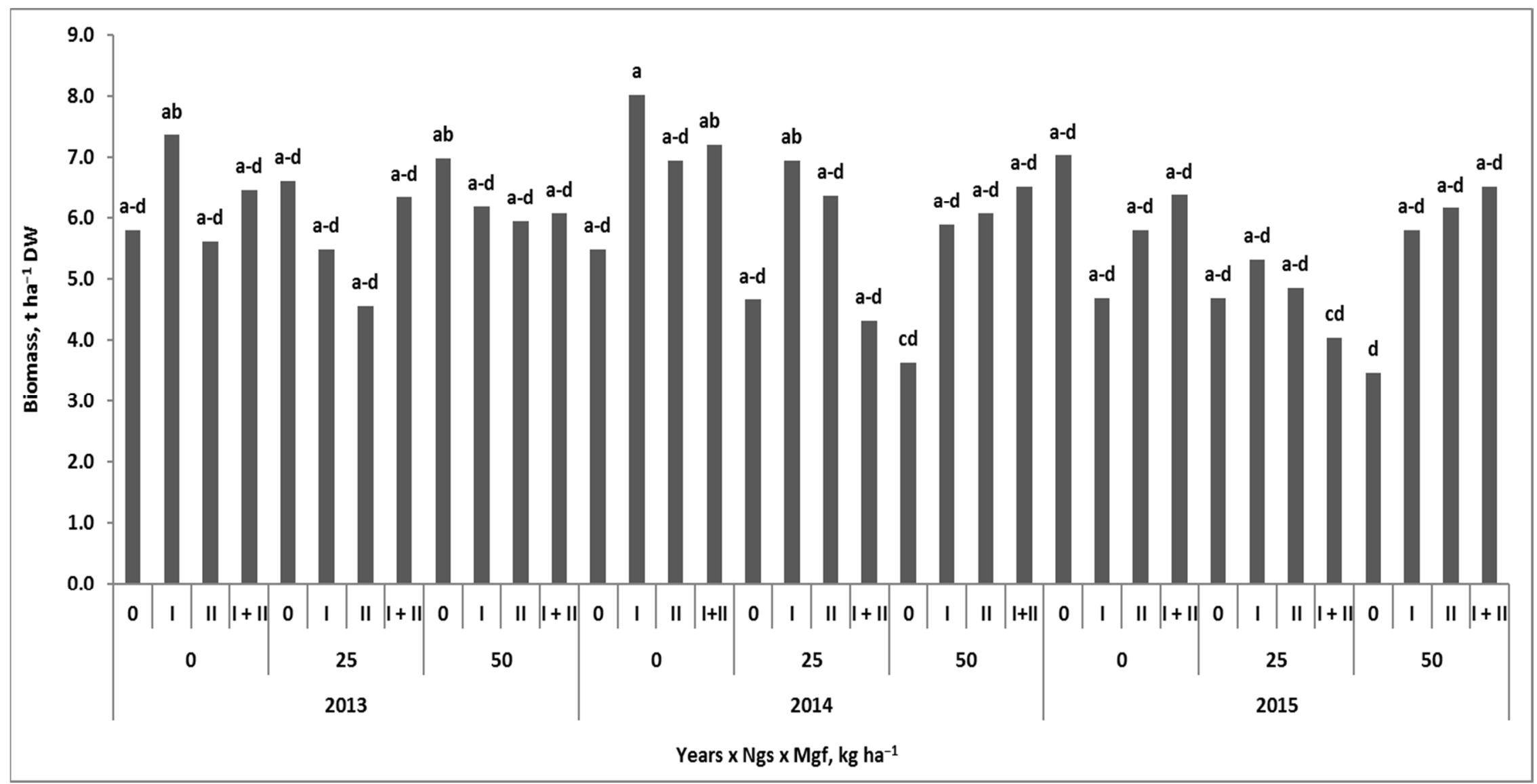

Figure 7. Effect of magnesium fertilization systems on the background of years on the current photosynthesis of winter wheat in the grain-filling period. Similar letters mean a lack of significant differences using Tukey's test. Legend: Mgs, Mgf—soil and foliar Mg fertilization systems, respectively; I-BBCH 30; II—BBCH $49 / 50$. 
The two-stage analysis of dry matter management by wheat during GFP showed much more complicated patterns of studied parameters of dry matter management during the GFP in response to Mg-FSs (Table 6). In 2013, REQ79 values were negative, which indicates a net increase in wheat biomass in the period from BBCH 58 to BBCH 79 (Figure 8). The net REQ value of $1.2 \mathrm{t} \mathrm{ha}^{-1}$ was recorded only on the plot with $25 \mathrm{~kg} \mathrm{Mg} \mathrm{ha}^{-1}$ and $\mathrm{Mg}-\mathrm{FF}$ at $\mathrm{BBCH} 49 / 50$. The opposite trend was observed in 2014 and 2015. The effect of $\mathrm{Mg}-\mathrm{FF}$ on REQ79 was nonsignificant compared to the effect of the soil-applied $\mathrm{Mg}$. In both years, the values of REQ79 gradually increased in response to the increased soil-applied Mg doses. The exception was the plot fertilized with $25 \mathrm{~kg} \mathrm{Mg} \mathrm{ha}^{-1}$ and with two-stage $\mathrm{Mg}-\mathrm{FF}$ in 2014 , showing the highest value of the index. The efficiency of dry matter remobilization (ReE79) was negative in 2013. In the remaining years, it was positive, but below $20 \%$. The share of remobilized dry matter to the grain yield (ReG79) was around 33\% in 2014, and $26 \%$ in 2015. It 2013, it reached negative values.

The values of the current photosynthesis at BBCH 79 (CP79) showed large differences between years (Table 6). In 2014, the index value was 37\%, and 21.6\% lower in 2015 than the highest recorded in 2013. The effect of Mg-FSs was variable in the studied years (Figure 9). In 2013, the highest CP values were recorded on the Mg-soil control plot, and that fertilized with $25 \mathrm{~kg} \mathrm{Mg} \mathrm{ha}^{-1}$. The higher dose of $\mathrm{Mg}$ applied to the soil resulted in a decrease in CP. A significant effect of $\mathrm{Mg}$-FF was observed on the $\mathrm{Mg}$-soil control plot, in which the two-stage Mg-FF resulted in the highest CP value. In 2014, CP values gradually decreased in response to the increasing dose of the soil-applied $\mathrm{Mg}$. This negative effect was reversed by Mg-FF. As in 2013, the lowest CP values were recorded on the plot treated with $50 \mathrm{~kg} \mathrm{Mg}$ $\mathrm{ha}^{-1}$. In 2015, the patterns of CP response to the soil-applied Mg were very similar to those observed in 2013. The effect of Mg-FF was much stronger on the plot with $50 \mathrm{~kg} \mathrm{Mg} \mathrm{ha}^{-1}$.

The efficiency of CP (CPE79) was the highest in 2013, reaching around 45\%. In 2014, it was $20 \%$ lower, and in 2015, 15\% lower. The share of CP in the grain yield (CPG79) was high, exceeding $100 \%$ in $2013,67 \%$ in 2014 , and $74 \%$ in 2015 . It is worth emphasizing that all indicators were significantly lower on plots with soil-applied $\mathrm{Mg}$. The decrease in the CP79 value by about $0.9 \mathrm{tha}^{-1}$, which was noted on the plots with soil-applied $\mathrm{Mg}$, compared to the Mg-soil control, resulted in a significant decrease in other CP indices.

The remobilization indices showed a positive relationships with the yield components, except TGW, which was negative. The reverse relationships were usually observed for CP indices (Table A3). The values of REQ79 and its derivatives significantly depended on the wheat biomass at $\mathrm{BBCH} 58$. The linear regression model looks similar to the following:

$$
\text { REQ79 }=-0.91 \mathrm{~T} 58-9.553 \text { for } n=36 . \mathrm{R}^{2}=0.87 \text { and } p \leq 0.01
$$


Table 6. Indices of winter wheat biomass partitioning during the periods of grain formation and maturation.

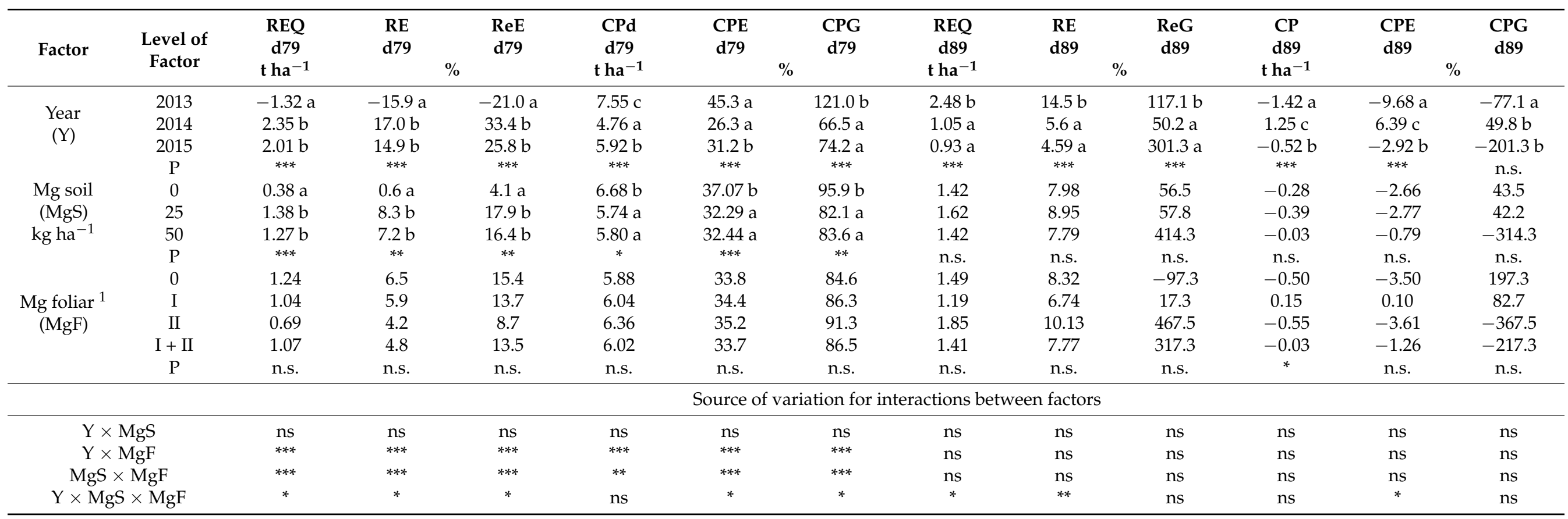

a, b, c similar letters mean a lack of significant differences using Tukey's test; ${ }^{* * *},{ }^{* *}$, and * indicate significant differences at $p<0.001, p<0.01$, and $p<0.05$, respectively; ns-nonsignificant. Legend: Mgs, Mgf—soil and foliar Mg fertilization systems, respectively; ${ }^{1}$ I-BBCH 30; II—BBCH 49/50; REQ—remobilization quota; RE—remobilization efficiency; ReG—contribution of REQ in the grain yield; $\mathrm{CP}$ - current photosynthesis; $\mathrm{CPE}$ - efficiency of $\mathrm{CP}$; $\mathrm{CPG}$ - contribution of CP in the grain yield; d79, d89-growth stages of winter wheat in accordance with the $\mathrm{BBCH}$ scale, referring to the respective periods of $\mathrm{BBCH} 58-\mathrm{BBCH} 79$ and $\mathrm{BBCH} 79-\mathrm{BBCH} 89$. 


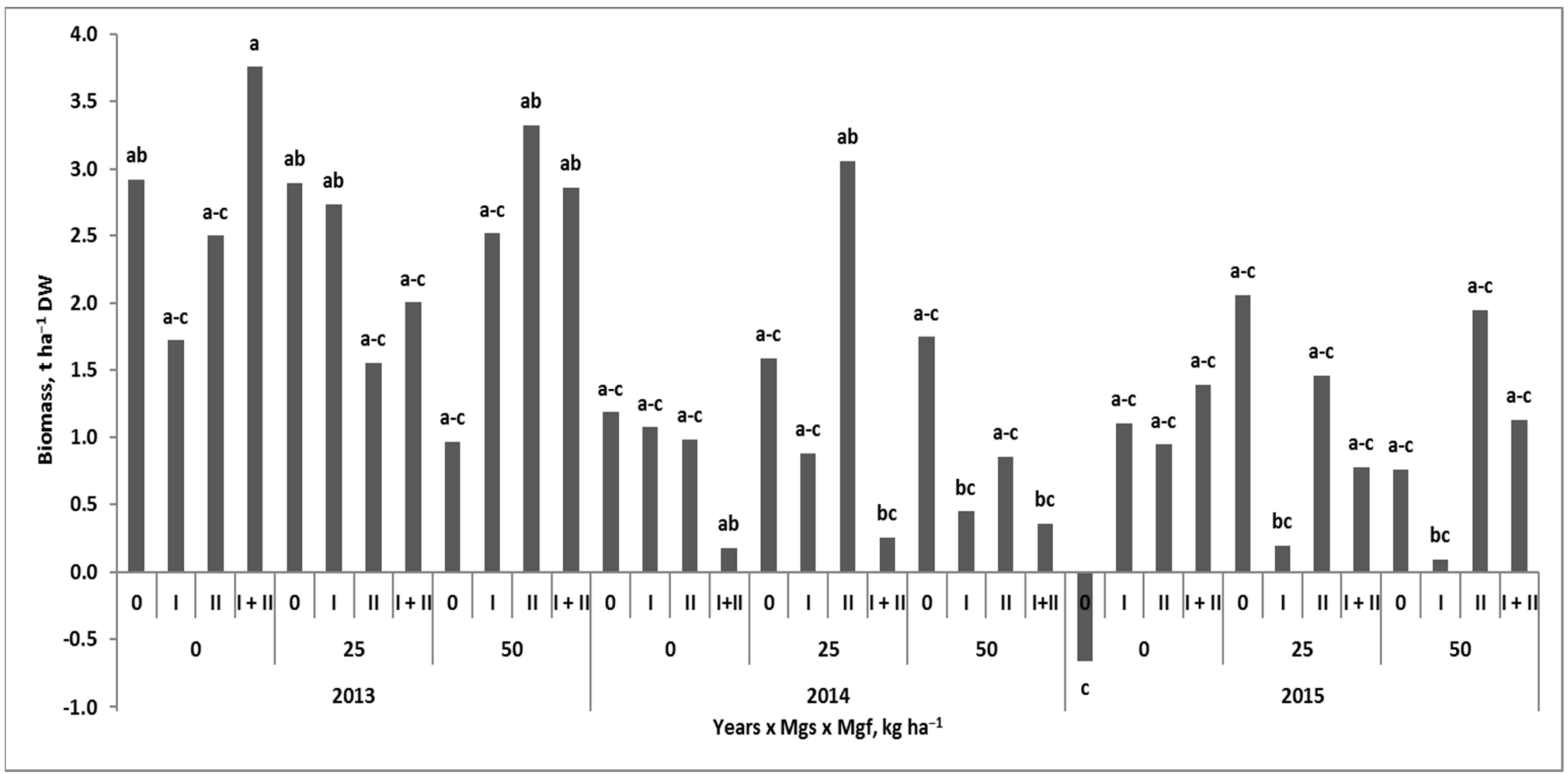

Figure 8. To BBCH 79. a,b,c similar letters mean a lack of significant differences using Tukey's test. Legend: Mgs, Mgf-soil and foliar Mg fertilization systems, respectively; I-BBCH 30; II-BBCH 49/50. 


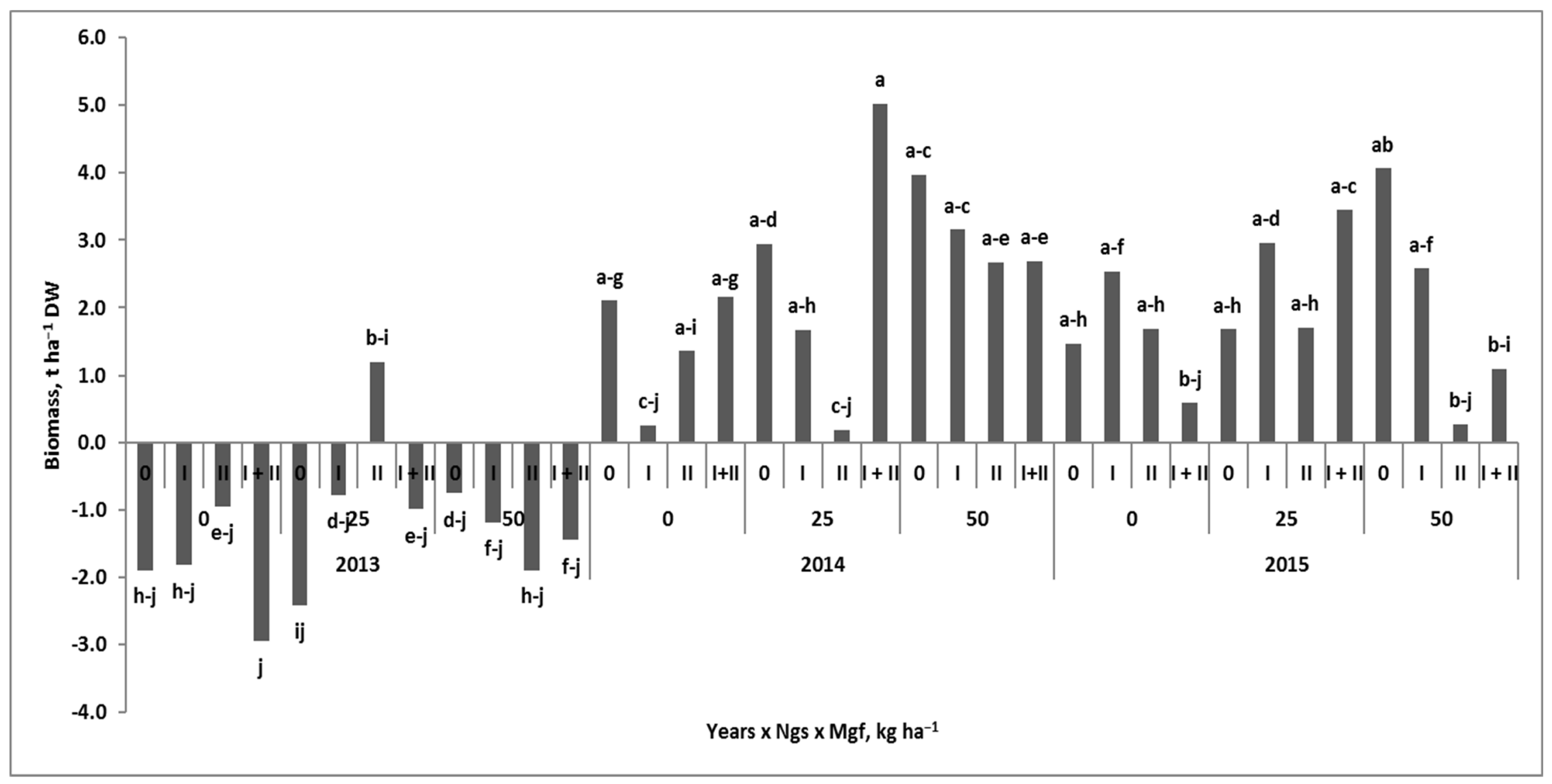

Figure 9. Effect of magnesium fertilization systems on the background of years on the current photosynthesis of winter wheat from $\mathrm{BBCH} 58$ to $\mathrm{BBCH} 79$. Similar letters mean a lack of significant differences using Tukey's test. Legend: Mgs, Mgf—soil and foliar Mg fertilization systems, respectively; I-BBCH 30; II—BBCH $49 / 50$. 
This model reports that the maximum wheat biomass of $9.553 \mathrm{t} \mathrm{ha}^{-1}$ at BBCH 58 was critical to obtain positive REQ79 values. The grain yield at $\mathrm{BBCH} 79$ and $\mathrm{BBCH} 89$ was positive, but poorly correlated with the remobilization indices (Table A3):

$$
\begin{gathered}
\text { GY79 }=-0.048 \text { REQ792 + 0.29REQ79 }+7.032 \text { for } n=36, \mathrm{R}^{2}=0.39 \text { and } p \leq 0.05 \\
\text { GY89 }=0.323 \text { REQ79 }+8.01 \text { for } n=36, \mathrm{R}^{2}=0.53 \text { and } p \leq 0.05
\end{gathered}
$$

The first equation (Equation (9)) clearly shows that GY79 increases gradually to $7.475 \mathrm{t} \mathrm{ha}^{-1}$, but only provided the simultaneous increase in REQ79 up to $3.046 \mathrm{t} \mathrm{ha}^{-1}$. Any higher value of REQ79 resulted in a slight GY79 decrease. The second equation (Equation (10)) clearly shows that any increase in REQ79 resulted in a linear increase in the final grain yield. The relationships between $\mathrm{CP}$ indices and wheat biomass at $\mathrm{BBCH} 58$ were as strong as in the case of REQ indices but showed a negative sign. The relationship between CP and GY79 was nonsignificant, but at the same time significant for GY89, and especially for dGY89. The negative sign of the correlation coefficient informs that each increase in CP value at $\mathrm{BBCH} 79$ resulted in a decrease in the grain yield.

The values of REQ89 in the wheat maturation phase (dREQ89), averaged for the experimental factors, were positive. The highest value was recorded in 2013. In 2014, dREQ89 reached 42.3\%, and in 2015 only 37.5\% of that in 2013 (Table 6). The effect of $\mathrm{Mg}$-FSs on this index was very variable in the subsequent years of the study (Figure 10). In 2013, dREQ89 depended on the Mg applied dose, and was significantly lower on the plot fertilized with $50 \mathrm{~kg} \mathrm{Mg} \mathrm{ha}^{-1}$. On the Mg-soil control, the highest dREQ89 was recorded on a plot with the two-stage Mg-FF application. The depressive effect of $\mathrm{Mg}$-FF on this index was recorded on the plot with $25 \mathrm{~kg} \mathrm{Mg} \mathrm{ha}^{-1}$. On the plot with $50 \mathrm{~kg} \mathrm{Mg} \mathrm{ha}^{-1}$, foliar-treated plants significantly increased dREQ89 compared to the Mg-foliar control. In 2014, this index showed a slight increase along the increasing dose of the soil-applied $\mathrm{Mg}$. The highest dREQ89 was recorded on the plot with $25 \mathrm{~kg} \mathrm{Mg} \mathrm{ha}^{-1}$ and with $\mathrm{Mg}-\mathrm{FF}$ at $\mathrm{BBCH}$ 30. In 2015, the positive effect of the soil-applied $\mathrm{Mg}$ was most visible on the plot with $25 \mathrm{~kg} \mathrm{Mg} \mathrm{ha}^{-1}$. The effect of Mg-FF was most significant on the plot fertilized with $50 \mathrm{~kg} \mathrm{Mg} \mathrm{ha}^{-1}$. The efficiency of dREQ89 (dReE89) was low. In 2013, this index reached approximately $15 \%$, and was three times higher than in the other two years. The values of the next index, i.e., the contribution of remobilized dry matter in the grain yield (dReG89), were extremely high, and ranged from 50\% in 2014 to over $100 \%$ in the remaining years of the study. The value of the current photosynthesis of wheat during the maturation phase (dCP89) was positive only in 2014. The effect of Mg-FF was revealed only at BBCH 30. There was no effect of the interaction between Mg-FSs and years on CP values. 


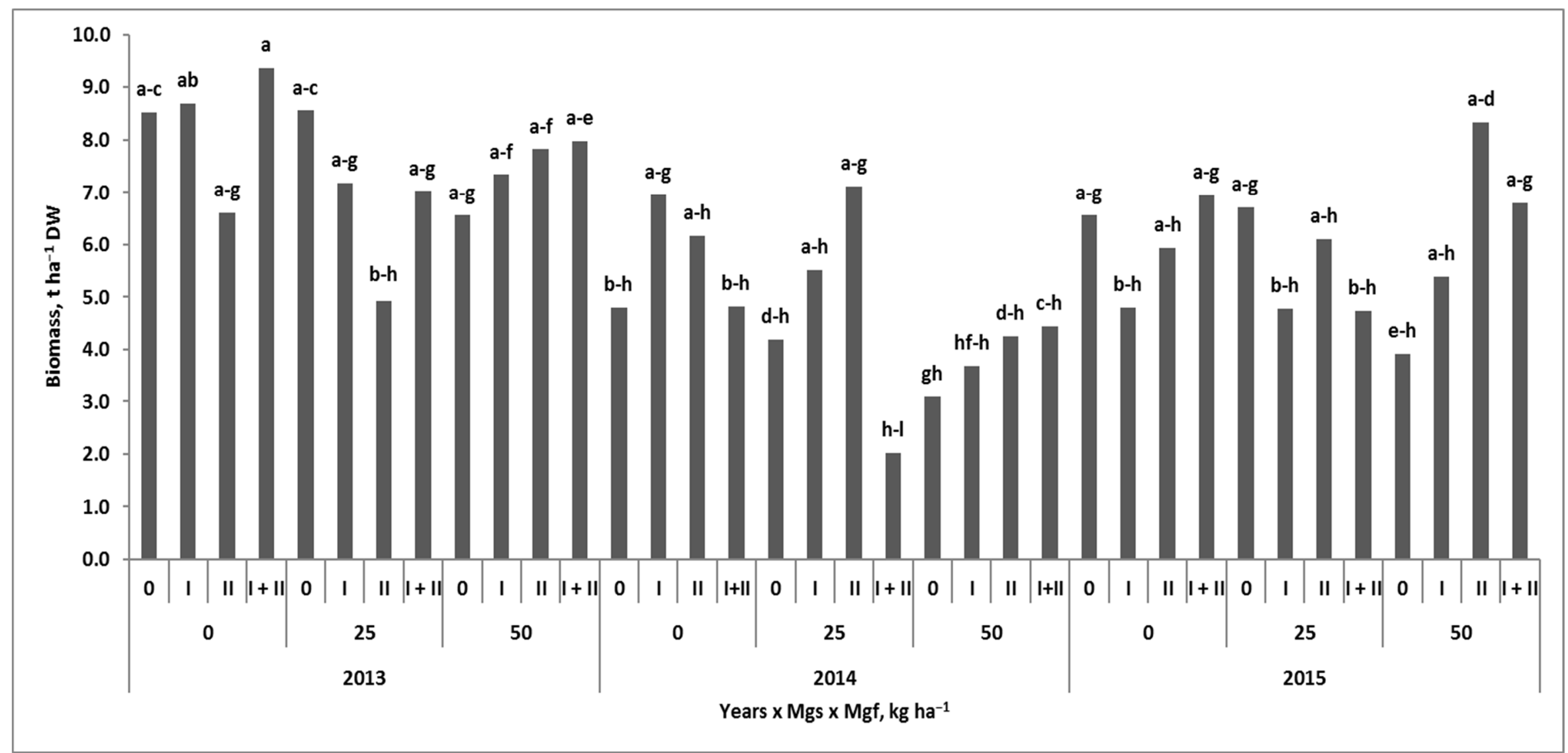

Figure 10. Effect of magnesium fertilization systems on the background of years on the remobilized dry matter of winter wheat in the maturation phase. Similar letters mean a lack of significant differences using Tukey's test. Legend: Mgs, Mgf—soil and foliar Mg fertilization systems, respectively; I-BBCH 30; II—BBCH $49 / 50$. 


\section{Discussion}

\subsection{Magnesium Fertilization Systems and Grain Yield Development during the Grain-Filling Period}

A frequently proposed agronomic option for increasing fertilizer $\mathrm{N}$ productivity, irrespective of the region of the world, is to reduce its dose $[32,39,40]$. However, the rigid solution, based on experimentally developed quadratic regression models, does not lead to the $\mathrm{N}$ rate optimization. The productivity of the fertilizer $\mathrm{N}$ can be compared, using the index of the partial factor of $\mathrm{N}$ productivity (PFP-N) [41]. PFP-N values for optimal N dose in the study by Belete et al. [40] and Tabak et al. [39] were 25 and $39 \mathrm{~kg}_{\text {grain kg }}{ }^{-1} \mathrm{~N}$, respectively. In our study, the value of PFP-N was $48 \mathrm{~kg}_{\text {grain }}$ per $\mathrm{kg}^{-1} \mathrm{~N}$ on a plot fertilized only with nitrogen in the rate of $190 \mathrm{~kg} \mathrm{ha}^{-1}$. This index on the plot with the soil-applied $\mathrm{Mg}$ and the two-stage $\mathrm{Mg}-\mathrm{FF}$, i.e., conducted at $\mathrm{BBCH} 30$ and repeated at $\mathrm{BBCH} 49 / 50$, reached the value of $53 \mathrm{~kg}_{\text {grain }} \mathrm{kg}^{-1} \mathrm{~N}$. The relative increase in the value of PFP-N due to $\mathrm{Mg}$ fertilization was $+10.4 \%\left(9.082 \rightarrow 9.998 \mathrm{t} \mathrm{ha}^{-1}\right)$

The study clearly showed that the application of $\mathrm{Mg}$, regardless on the fertilization system, resulted in a significant increase in the wheat yield. The effect of sulfur in the applied Mg fertilizers (Mg sulfates) was eliminated by using its balanced dose in the NS fertilizers. Wheat cultivated on soil with a medium content of available $\mathrm{Mg}$ responded to both soil and foliar application of $\mathrm{Mg}$. Its dose of $25 \mathrm{~kg} \mathrm{ha}^{-1}$ increased the yield by $0.5 \mathrm{t} \mathrm{ha}^{-1}$. A slightly better effect was achieved with the foliar $\mathrm{Mg}$ application, which resulted in the yield gain of $+0.7 \mathrm{t} \mathrm{ha}^{-1}$. However, the highest increase in the grain yield of $0.9 \mathrm{t} \mathrm{ha}^{-1}$ was recorded, provided applying $50 \mathrm{~kg} \mathrm{Mg} \mathrm{ha}^{-1}$ to the soil, and foliar fertilization with $\mathrm{Mg}$ in two stages of wheat growth, i.e., BBCH 30 and BBCH 49/50. The increase in the yield due to $\mathrm{Mg}$ application in this system was in the upper part of the often noted range (5-15\%) [35].

The positive effect of $\mathrm{Mg}$ application on the grain yield of wheat can be explained by its influence on the structural components of the yield. The study clearly showed that the use of $\mathrm{Mg}$, regardless of the method of its application, resulted in an increase of grain density (GD). The variability in this wheat trait explained $95 \%$ of the grain yield variability (Equation (1). The wheat grain yield was negatively correlated with TGW $(r=-0.79$, Table A1). This phenomenon was due to the compensation mechanisms between GD and TGW. The lower GD in 2013 resulted in the significantly higher TGW compared to 2014 $(+12.2 \%)$. The dominated effect of GD on the grain yield confirms the importance of this trait for high-yielding wheat varieties [16,42]. The increase in GD depended on the response of two basic yield components, i.e., ear density (ED) and the number of grains per ear (GR), to magnesium fertilization systems (Mg-FSs). Both these traits showed a significant, and positive response to Mg-FSs (Table 3). The greatest increase in GD, observed at BBCH 30, resulted from the simultaneous response of basic yield components, i.e., ED and GR to magnesium application. A further increase in GD was obtained under the condition of repeated foliar fertilization of wheat with magnesium at both $\mathrm{BBCH} 30$ and $\mathrm{BBCH} 49 / 50$. This type of GD response indirectly stresses the effect of $\mathrm{Mg}$ on the processes responsible for ear formation during the booting phase. This phase is crucial for the ear formation [7,43].

The temporary grain yield of wheat, as determined at BBCH 79, as well as its increment in the wheat maturation phase, was significantly influenced by interaction of Mg-FSs. The temporary grain yield, i.e., GY79, showed a positive relationship with ED, but at the same time negative correlation with TGW. It should be added that ED was the dominant factor affecting GY79. The increase in wheat grain yield during the maturation phase showed a positive relationship with GR. At the same time, the correlation with TGW was negligible. This set of relationships directly emphasizes the importance of GD as a yield component that determines the yield of wheat. This confirms that the physiological sink dominates over the source in the development of the wheat grain yield [44-46].

The grain yield at BBCH 79 was the highest in 2015, reaching $7.9 \mathrm{t} \mathrm{ha}^{-1} \mathrm{DW}$, and constituted $95 \%$ of its final yield, i.e., at wheat maturity. The yield increment in the maturation phase was low, reached an average of $0.41 \mathrm{t} \mathrm{ha}^{-1}$, mainly due to foliar-applied 
$\mathrm{Mg}$ (Figure 6). The main reason for the low yield increase in this phase was the drought, covering periods responsible for both GR and TGW [7,47]. The negative effect of drought, often associated with the thermal stress, is a strong factor, leading to grain abortion and a decrease in TGW [15]. In our study, the effect of drought revealed a relatively low TGW, despite the low GR, indirectly suggesting no compensation effect. The highest yield increment in wheat maturation, amounting to $2.3 \mathrm{t} \mathrm{ha}^{-1}$, was recorded in 2014 . The GY79 on average reached $7.1 \mathrm{tha}^{-1}$ and constituted $76 \%$ of the final wheat yield at maturity. The key reasons for the high yield increase were as follows:

a. Very high GD, which increased due to Mg application from 24,000 to 30,000 grains per $\mathrm{m}^{2}$.

b. Favorable growth conditions throughout the whole wheat vegetation.

The first point clearly indicates that the use of $\mathrm{Mg}$ resulted in the increase of the size of the wheat physiological sink. The net yield increase was $0.7-0.8 \mathrm{t} \mathrm{ha}^{-1}$ compared the absolute $\mathrm{Mg}$-control, i.e., for plants fertilized only with $\mathrm{N}$. This increase was recorded on the plots fertilized with $\mathrm{Mg}$ in the dual way, i.e., soil and foliar.

\subsection{Magnesium Fertilization Systems and Sink-Source Relationships during the Grain-Filling Period}

The critical period of wheat grain yield development begins about 20 days before the onset of flowering [45]. The study takes into account the structure of wheat biomass in the period from $\mathrm{BBCH} 58$ to $\mathrm{BBCH} 89$. At the beginning of this period, the main constituents of wheat were leaves, which are the pure physiological source, stems as a storage for assimilates, and ears as a temporary sink and final source of assimilates for the growing grains, which are a pure physiological sink. The end of heading and flowering are generally considered to be decisive for the final size of the wheat sink, i.e., GD [18,48]. Overall, both GY79 and GY89 were significantly dependent on total wheat biomass at BBCH 58 (Table A2). The regression models are as follows:

$$
\begin{gathered}
\text { GY79 }=-0.053 T 58^{2}+1.453 \mathrm{~T} 58-2.44 \text { for } n=36 . \mathrm{R}^{2}=0.56 \text { and } p \leq 0.05 \\
\text { GY89 }=-0.053 \mathrm{~T} 58+4.327 \text { for } n=36 . \mathrm{R}^{2}=0.64 \text { and } p \leq 0.01
\end{gathered}
$$

This first model reports that the maximum GY79 of $7.517 \mathrm{tha}^{-1}$ was obtained provided the T58 reached $13.7 \mathrm{t} \mathrm{ha}^{-1} \mathrm{DW}$. The second model is a linear GY89 response to the total wheat biomass at $\mathrm{BBCH} 58$. The detailed analysis of the effect of wheat constituents on GY79 showed that both leaves and ears/chaffs at BBCH 58/79 were the key organs of wheat, affecting both the temporary and the final wheat grain yield at $\mathrm{BBCH} 79$ (Figure 6). The obtained model clearly shows that in the period covering the key stages of grain yield development, i.e., late heading, flowering, and milking, the leaf biomass was highly stable. The observed persistence in leaf biomass indirectly indicates high photosynthetic activity of leaves $[49,50]$. The observed reduction of this wheat trait was stronger in the maturation phase than in the grain growth phase. The stem biomass during GFP did not prove to be a significant yield prognostics factor, but it was an important source of assimilates to the growing grains during the GFP. The yield-forming effect of dry matter recovered from the stem is well understood [21-23]. In our study, the importance of this source of assimilates depended on the course of the weather. It was the weakest in the dry 2015, which is contradictory to the hypothesis by van Herwaarden et al. [51]. The conducted study has clearly shown that chaffs are the first source of assimilates to the growing grains. The negative impact of the chaff biomass on GY79 reflects the degree of remobilization of the biomass from the ear. This process was the strongest $(-43 \%)$ in 2015 in the phase of the grain growth. In 2014, there was also a slight decrease in ear biomass in this period. This set of processes clearly confirms the yield-forming role of the ear in the early stages of the grain formation $[13,16]$. 
The temporary wheat yield, i.e., GY79, was significantly dependent on ED, but, at the same time, not on GD. This trait was positively correlated with the wheat biomass at BBCH 58 and its constituents. Each year, wheat biomass at the onset of flowering significantly responded to $\mathrm{Mg}-\mathrm{FS}$. The soil-applied $\mathrm{Mg}$ showed an advantage over foliar application on grain components of wheat yield. The only exception was the leaf biomass, which had the highest values each year, provided soil-applied $\mathrm{Mg}$ at the rate of $25 \mathrm{~kg} \mathrm{ha}^{-1}$ and concomitant foliar Mg application. Therefore, ED can be treated as the main efficiency factor, affecting the size of the physiological wheat sink at BBCH 79. Positive relationships between the increase in grain yield in the wheat maturation phase and GD resulted from the effect of $\mathrm{Mg}$ on GR. It can be, therefore, concluded that the effect of $\mathrm{Mg}$, regardless of the application method, results in both an increase in the sink strength and the durability of the leaves. This is possibly an agronomic way to increase the grain yield. This study clearly confirms the hypothesis by Körner [46] that sink strength affects the activity of the source.

\subsection{Magnesium Fertilization Systems and Indices of Dry Matter Management during the Grain-Filling Phase}

An important objective of the study was to assess the impact of $\mathrm{Mg}$ fertilization systems on the contribution of both sources of assimilates, i.e., the remobilized dry matter (REQ) and the current photosynthesis (CP) in the grain yield. The studies carried out so far have shown that the activation of carbohydrate from the vegetative parts of wheat takes place under optimal environmental conditions only 20-50 days after the beginning of flowering. Thus, for most of the period of grain growth, the key determinant of the yield increment is CP $[52,53]$. The conducted study clearly showed that CP was the main source of assimilates for developing grains, determining, on average, $66 \%$ of the final grain yield. The remaining part, i.e., 34\%, was supplied from dry matter remobilized from vegetative wheat parts.

The key question, however, is what the effect of these two sources of assimilates is on the grain yield formation. The applied two-stage analysis showed a high complexity of this process. Hence, the impact of Mg-FSs on the formation of wheat grain yield during the grain-filling period was assessed by analyzing the following:

(1) The size of the sink, expressed as the ED, GR, and finally by GD.

(2) Weather conditions in the periods responsible for the formation of wheat yield components.

(3) Phases of grain growth.

The effect of the sink size on the amount of dry matter remobilized from the vegetative wheat organs was the strongest in 2013 and 2014. The key reason for the significantly lower yield in 2013 was a too-insufficient sink size, expressed by GD. Grain density in 2013 was $32.5 \%$ lower than in 2014 , but the difference between the yields was only $21.6 \%$. It has been well documented that the amount of assimilates at the beginning of wheat flowering supplied to the growing grains, as a rule, must be large enough to cover the demand of the growing grain [54]. In 2013, the resources of assimilates in the vegetative parts of wheat were not used by plants in the early stages of grain enlargement. The key reason was a too-low size of the sink, i.e., GD. Thus, the main source of assimilates was the current photosynthesis (Figure 11). In 2014, reverse processes were observed. A much-larger GD caused the activation of assimilate resources from all vegetative parts of wheat, but most was from the stem. The importance of the stem as a source of assimilates is confirmed by a $23 \%$ decrease in the stem biomass from BBCH 58 to BBCH 79. The impact of Mg-FSs was very specific. As a rule, the soil-applied $\mathrm{Mg}$ increased the share of the remobilized dry matter from $30 \%$ by $41 \%$ to $56 \%$ on the Mg-soil control, and plots fertilized with 25 and $50 \mathrm{~kg} \mathrm{Mg} \mathrm{ha}{ }^{-1}$, respectively. 


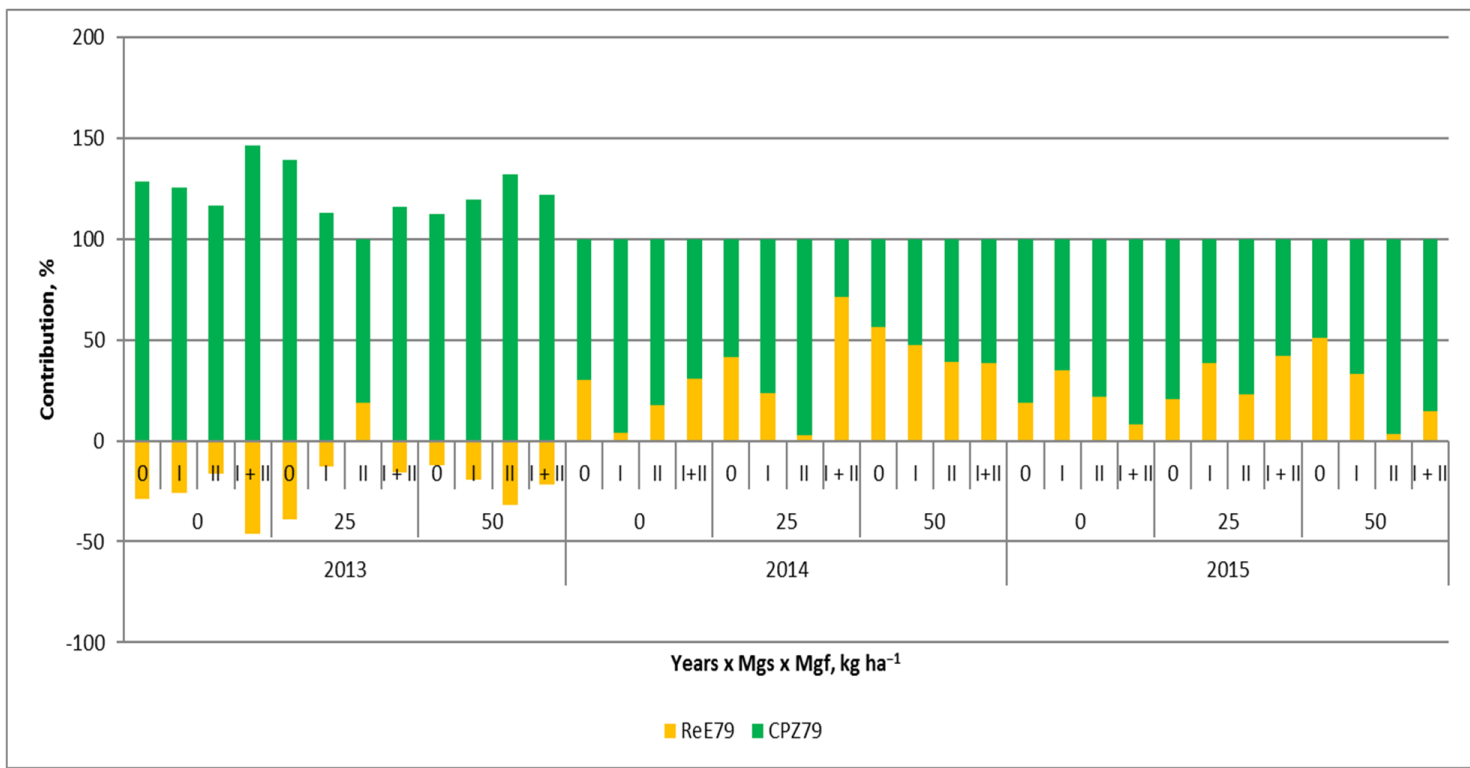

Figure 11. Effect of magnesium fertilization systems, on the background of years, on contribution of the remobilized dry matter and the current photosynthesis in the temporary grain yield at $\mathrm{BBCH} 79$. Legend: Mgs, Mgf—soil and foliar Mg fertilization systems, respectively; I-BBCH 30; II-BBCH $49 / 50$.

The second point concerns the impact of contrastive weather conditions on the relative share of both assimilate sources in the wheat grain yield. The explanation requires focusing on the development stage of the grain yield formation. The temporary grain yield, as assessed at $\mathrm{BBCH} 79$, responded differently to the weather course. In 2014, favorable for wheat, as explained in the previous section, the share of remobilized dry matter was significantly affected by the application of magnesium, reaching maximum of $72 \%$ on the plot treated with $25 \mathrm{~kg} \mathrm{Mg} \mathrm{ha}^{-1}$ and its repeated foliar fertilization at $\mathrm{BBCH} 30$ and BBCH 49/50 (Figure 12). In the dry 2015, the maximum share of remobilized dry matter in the grain yield was $51 \%$ on the plot fertilized with the soil-applied $\mathrm{Mg}$ in the dose of $50 \mathrm{~kg} \mathrm{Mg} \mathrm{ha}{ }^{-1}$. Foliar fertilization with $\mathrm{Mg}$ increased the share of remobilized dry matter, but only on plots without or with a low rate of the soil-applied magnesium.

In the wheat maturation phase, in two of three years of the study, the main source of assimilates was their resources in the vegetative organs (Figure 12). The main organs, supplying assimilate to growing grains, were leaves and stems (Table 2). The average decline in the leaf biomass was 26\% in 2013 and 16\% in 2015. In 2013, the key source was stems, as indicated by the substantial decrease in dry matter content of $34 \%$. However, these processes did not result a significant increase in the final grain yield. The largest increase in the yield, as recorded in 2014, resulted from the photosynthetic activity of plants, which contributed $50 \%$ to the increase in the total grain yield. In this year, in contrast to the other two, the share of CP in the grain yield increased on plots fertilized intensively with magnesium, i.e., responding to both soil and foliar its application.

The dry matter remobilization indices in the period from $\mathrm{BBCH} 58$ to $\mathrm{BBCH} 89$ were significantly correlated with wheat biomass at the beginning of this period, i.e., $\mathrm{BBCH}$ 58 (Table A2). This strong correlation indirectly confirms the conclusion presented in the previous chapter about the importance of this stage of wheat growth for the final grain yield. Hence, the trends recorded in the $\mathrm{BBCH} 58-\mathrm{BBCH} 79$ period determined the final structure of assimilate sources for growing grain. This conclusion is supported by the significant dependence of the total share of remobilized dry matter on its share in the grain growth phase:

$$
\operatorname{ReG89}=0.43 \operatorname{ReG} 79+23.6 \text { for } n=36, \mathrm{R}^{2}=0.69 \text { and } p \leq 0.01
$$




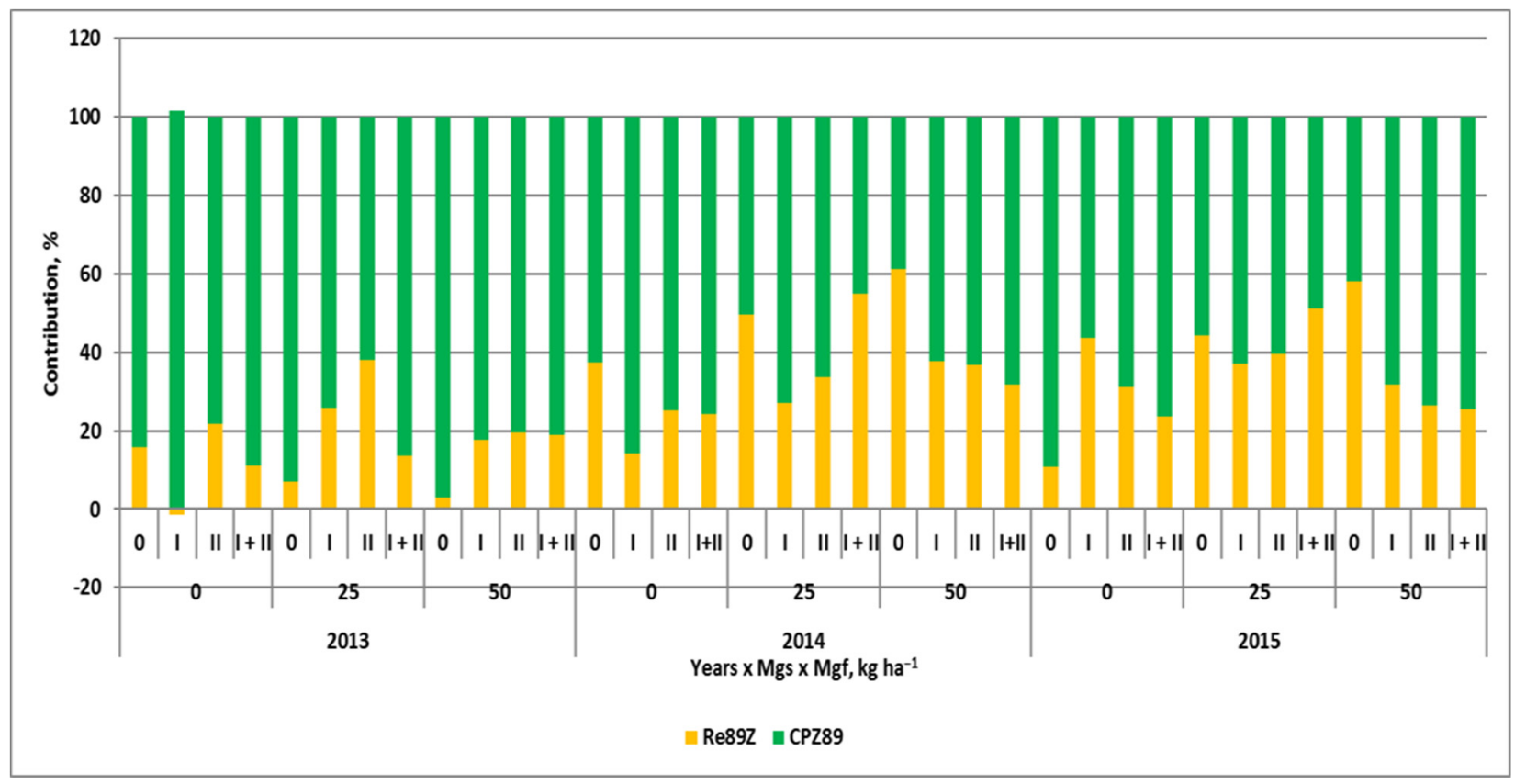

Figure 12. Effect of magnesium fertilization systems, on the background of years, on contribution of the remobilized dry matter and the current photosynthesis in the grain yield at $\mathrm{BBCH} 89$. Legend: Mgs, Mgf—soil and foliar Mg fertilization systems, respectively; I-BBCH 30; II—BBCH 49/50.

The presented results contradict the common opinion that such a large activation of assimilate reserves takes place only under stressful conditions [19,20]. The observed phenomenon can be only explained by the luxurious status of wheat resulting from the supply of $\mathrm{Mg}$ to wheat from the beginning of its growth. Magnesium in a seed plant is responsible for phloem-loading and long-distance transport of photoassimilates [55]. The increase in the share of CP in the grain yield in response to foliar Mg application, as observed on both the plot with high dose of the soil-applied $\mathrm{Mg}$ and its application to the wheat foliage, can be explained by the induction of the rate of starch transport from leaves to grains [56].

The conducted study concerned the response of one wheat variety to $\mathrm{Mg}$ fertilization systems, i.e., in soil and foliar. The lack of Mg-FSs interaction with years suggests a stable effect of magnesium fertilization on the yield of wheat grain, regardless of weather conditions. This conclusion corresponds with Grzebisz's [34] early studies. However, modern wheat genotypes are very sensitive to environmental factors [57]. Ljubicic et al. [58] showed that wheat genotypes differ in their response both to stressful environmental conditions and the applied ameliorative measures. In the light of the data obtained, further study is needed on the response of various wheat genotypes to confirm the spectacular effect of magnesium used in wheat cultivation.

\section{Conclusions}

Fertilizing winter wheat with magnesium, regardless of the method of application, i.e., in soil or foliar, resulted in a significant increase in the grain yield. The interaction of these methods enabled an increase in the grain yield by $10 \%$, compared to the effect of nitrogen fertilizer applied alone. The increase in the grain yield was due to the increase in grain density (GD). This wheat trait was driven by the ear density (ED), and/or by the number of grains per ear (GR). The soil-applied $\mathrm{Mg}$, concomitant with the two-stage Mg foliar fertilization, i.e., carried out at $\mathrm{BBCH} 30$ and repeated at $\mathrm{BBCH} 49 / 50$, resulted in the highest sink density, expressed by GD. The temporary grain yield of wheat determined at BBCH 79 was $6.2,7.1$, and $7.9 \mathrm{t} \mathrm{ha}^{-1}$, in 2013, 2014, and 2015, respectively. The corresponding grain yield increase in the maturation phase of wheat was $1.0,2.3$, and $0.4 \mathrm{t} \mathrm{ha}^{-1}$, respectively. 
The average share of the remobilized dry matter (REQ) and current photosynthesis (CP) in the final grain yield was $34 \%$ and $66 \%$. The share of REQ in the grain yield significantly depended on the stage of the grain yield formation, the magnesium fertilization system, and the course of the weather in a given growing season. The grain yield and its structural components depended on the wheat biomass at the onset of flowering (BBCH 58). The increase in the share of REQ in the yield was enormous and ranged from $30 \% / 18 \%$ on the Mg-control to 56\%/51\% on the plot with $\mathrm{Mg} 50 \mathrm{~kg}^{-1}$ in 2014 and 2015, respectively. The foliar application of $\mathrm{Mg}$ resulted in the increased participation of $\mathrm{CP}$ in the grain yield, simultaneously decreasing the share of REQ. The increase in the grain yield in the wheat maturation phase in the years with low GD or under stress conditions $(2013,2015)$ depended on REQ. In a year with favorable growth conditions (2014), characterized by a well-formed GD, both source of assimilates contributed to the increase in yield.

Author Contributions: Conceptualization, W.G. and J.P.; methodology, W.G. and J.P.; software, J.P.; validation, J.P. and W.G.; formal analysis, W.G.; investigation, J.P.; data curation, W.G.; writingoriginal draft preparation, J.P.; writing-review and editing, W.G.; visualization, W.G.; supervision, W.G.; project administration, J.P. All authors have read and agreed to the published version of the manuscript.

Funding: This research received no external funding.

Institutional Review Board Statement: Not applicable.

Informed Consent Statement: Not applicable.

Data Availability Statement: Not applicable.

Conflicts of Interest: The authors declare no conflict of interest.

\section{Appendix A}


Table A1. Matrix of correlation indices for winter wheat biomass components, $n=36$.

\begin{tabular}{|c|c|c|c|c|c|c|c|c|c|c|c|c|c|c|}
\hline Trait & ST58 & EA58 & LE79 & ST79 & CH79 & GY79 & LE89 & ST89 & CH89 & GY89 & ED & GR & GD & TGW \\
\hline LE58 & $0.89 * * *$ & $0.66^{* * *}$ & $0.77^{* * *}$ & $-0.35 *$ & $0.35 *$ & $0.55^{* * *}$ & $0.79^{* * *}$ & $0.48^{* *}$ & 0.27 & $0.91 * * *$ & $0.70^{* * *}$ & $0.42 *$ & $0.84^{* * *}$ & $-0.81^{* * *}$ \\
\hline ST58 & 1.00 & $0.70^{* * *}$ & $0.67^{* * *}$ & -0.32 & 0.25 & $0.61^{* * *}$ & $0.76^{* * *}$ & $0.56^{* * *}$ & 0.15 & $0.83^{* * *}$ & $0.74^{* * *}$ & 0.30 & $0.77^{* * *}$ & $-0.80 * * *$ \\
\hline EA58 & & 1.00 & $0.61^{* * *}$ & 0.17 & -0.24 & $0.77^{* * *}$ & $0.70^{* * *}$ & $0.75^{* * *}$ & $-0.38 *$ & $0.47^{* *}$ & $0.76^{* * *}$ & -0.26 & 0.34 * & $-0.69^{* * *}$ \\
\hline LE79 & & & 1.00 & -0.08 & 0.29 & $0.70^{* * *}$ & $0.86^{* * *}$ & $0.63^{* * *}$ & 0.06 & $0.79^{* * *}$ & $0.73^{* * *}$ & 0.21 & $0.70^{* * *}$ & $-0.78^{* * *}$ \\
\hline ST79 & & & & 1.00 & -0.33 & 0.18 & -0.15 & 0.15 & $-0.42 *$ & $-0.41 *$ & -0.12 & $-0.51 * *$ & $-0.49 * *$ & 0.24 \\
\hline Ch79 & & & & & 1.00 & -0.17 & 0.14 & -0.22 & $0.72 * * *$ & $0.49^{* *}$ & -0.04 & $0.72 * * *$ & $0.55^{* *}$ & -0.11 \\
\hline GY79 & & & & & & 1.00 & $0.81^{* * *}$ & $0.85^{* * *}$ & $-0.41^{*}$ & $0.46^{* *}$ & $0.83^{* * *}$ & $-0.35^{*}$ & 0.32 & $-0.73^{* * *}$ \\
\hline LE89 & & & & & & & 1.00 & $0.78^{* * *}$ & -0.09 & $0.77^{* * *}$ & $0.88^{* * *}$ & 0.07 & $0.70^{* * *}$ & $-0.90^{* * *}$ \\
\hline ST89 & & & & & & & & 1.00 & $-0.42 *$ & $0.41 *$ & $0.86^{* * *}$ & $-0.41 *$ & 0.30 & $-0.72 * * *$ \\
\hline Ch89 & & & & & & & & & 1.00 & $0.42 *$ & -0.19 & $0.85^{* * *}$ & $0.55^{* * *}$ & 0.05 \\
\hline GY89 & & & & & & & & & & 1.00 & $0.68^{* * *}$ & $0.58^{* * *}$ & $0.95^{* * *}$ & $-0.79 * * *$ \\
\hline ED & & & & & & & & & & & 1.00 & -0.14 & $0.62 * * *$ & $-0.87^{* * * *}$ \\
\hline GR & & & & & & & & & & & & 1.00 & $0.69 * * *$ & -0.10 \\
\hline GD & & & & & & & & & & & & & 1.00 & $-0.71^{* * *}$ \\
\hline
\end{tabular}

$* * *, * *$, and $*$ indicate significant differences at $p<0.001, p<0.01$, and $p<0.05$, respectively; n.s. = not significant. Legend: LE, ST, EA, CH, T-biomass of leaves, stems, ears, chaffs, total, grain; 58, 78, 89-growth stages of winter wheat in accordance with the BBCH scale; ED—ears density; GR—grain per ear; GD—grain density; TGW—-thousand grain weight.

Table A2. Matrix of correlation indices for winter wheat remobilization indices during the grain-filling period, $n=36$.

\begin{tabular}{|c|c|c|c|c|c|c|c|c|c|c|c|c|c|c|c|}
\hline Trait & T79v & GY79 & T79 & Tv89 & GY89 & REQ89 & RE89 & $\operatorname{Re} 89 \mathrm{Z}$ & CP89 & СРС89 & CPZ89 & ED & GR & GD & TGW \\
\hline T58 & 0.24 & $0.70^{* * *}$ & $0.56^{* * *}$ & $0.79 * * *$ & $0.80^{* * *}$ & $0.89^{* * * *}$ & $0.82^{* * *}$ & $0.85^{* * *}$ & $-0.51^{* *}$ & $-0.90 * * *$ & $-0.85^{* * *}$ & $0.80^{* * *}$ & 0.16 & $0.70^{* * *}$ & $-0.84^{* * *}$ \\
\hline $\mathrm{T} 79 \mathrm{v}$ & 1.00 & $0.43^{* *}$ & $0.86^{* * *}$ & $0.37 *$ & 0.23 & 0.09 & 0.06 & 0.07 & 0.08 & -0.13 & -0.07 & 0.24 & -0.05 & 0.14 & -0.26 \\
\hline GY79 & & 1.00 & $0.84^{* * *}$ & $0.80^{* * * *}$ & $0.46^{* *}$ & $0.45^{* *}$ & $0.36^{*}$ & $0.44^{* *}$ & -0.20 & $-0.57^{* * *}$ & -0.44 & $0.83^{* * *}$ & -0.35 * & 0.32 & $-0.73^{* * *}$ \\
\hline T79 & & & 1.00 & $0.70^{* * *}$ & $0.40 *$ & 0.31 & 0.25 & 0.30 & -0.07 & $-0.41 *$ & -0.30 & $0.63^{* * *}$ & -0.23 & 0.27 & $-0.56^{* * *}$ \\
\hline Tv89 & & & & 1.00 & $0.70^{* * *}$ & $0.42 *$ & 0.30 & $0.36^{*}$ & 0.04 & $-0.49 * *$ & $-0.36^{*}$ & $0.91 * * *$ & -0.05 & $0.63 * * *$ & $-0.84^{* * *}$ \\
\hline GY89 & & & & & 1.00 & $0.66^{* * * *}$ & $0.60^{* * *}$ & $0.54 * *$ & -0.02 & $-0.54^{* *}$ & $-0.54^{* *}$ & $0.68^{* * *}$ & $0.58^{* * *}$ & $0.95^{* * *}$ & $-0.79 * * *$ \\
\hline REQ89 & & & & & & 1.00 & $0.98^{* * *}$ & $0.99^{* * *}$ & $-0.77^{* * *}$ & $-0.96^{* * *}$ & $-0.99 * * *$ & $0.51^{* *}$ & 0.27 & $0.57^{* * *}$ & $-0.61^{* * *}$ \\
\hline RE89 & & & & & & & 1.00 & $0.98^{* * *}$ & $-0.79 * * *$ & $-0.94 * * *$ & $-0.98^{* * *}$ & $0.43 *$ & 0.28 & $0.52 * *$ & $-0.53^{* *}$ \\
\hline $\operatorname{Re} 89 \mathrm{Z}$ & & & & & & & & 1.00 & $-0.85^{* * *}$ & $-0.98^{* * *}$ & $-1.00^{* * *}$ & $0.48^{* *}$ & 0.16 & $0.46^{* *}$ & -0.56 ** \\
\hline СР89 & & & & & & & & & 1.00 & $0.81^{* * *}$ & $0.85^{* * *}$ & -0.11 & 0.13 & 0.05 & 0.14 \\
\hline СРС 89 & & & & & & & & & & 1.00 & $0.98^{* * *}$ & $-0.59 * * *$ & -0.03 & $-0.44^{* *}$ & $0.63^{* * *}$ \\
\hline CPZ89 & & & & & & & & & & & 1.00 & $-0.48^{* *}$ & -0.16 & $-0.45^{* *}$ & 0.55 ** \\
\hline ED & & & & & & & & & & & & 1.00 & -0.14 & $0.62 * * *$ & $-0.87^{* * *}$ \\
\hline GR & & & & & & & & & & & & & 1.00 & $0.69 * * *$ & -0.10 \\
\hline GD & & & & & & & & & & & & & & 1.00 & $-0.71^{* * *}$ \\
\hline
\end{tabular}

***,**, and * indicate significant differences at $p<0.001, p<0.01$, and $p<0.05$, respectively; n.s. = not significant. Legend: T58, T79, T89-total wheat biomass at BBCH 58, 79, 89; GY79, GY89-grain yield at BBCH 79 and 89; T79v, T89v, total vegetative biomass of wheat; REQ—remobilization quota; RE—remobilization efficiency; ReG—contribution of remobilized dry matter to grain mass; $\mathrm{CP}$-current photosynthesis; $\mathrm{CPE}$ - efficiency of current photosynthesis; CPG—contribution of CP to grain mass; 78. 89-growth stages of winter wheat in accordance with the BBCH scale; ED—ears density; GR—grain per ear; GD—grain density; TGW—-thousand grain weight. 
Table A3. Matrix of correlation indices for winter wheat remobilization indices during the period of grain formation and maturation, $n=36$.

\begin{tabular}{|c|c|c|c|c|c|c|c|c|c|c|c|c|c|c|c|c|c|c|c|c|}
\hline Trait & GY89 & dGY89 & Tv79 & Tv89 & $\begin{array}{l}\text { REQ } \\
\text { d79 }\end{array}$ & $\begin{array}{l}\text { ReE } \\
\text { d79 }\end{array}$ & 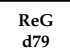 & $\begin{array}{l}\text { CP } \\
\text { d779 }\end{array}$ & $\begin{array}{l}\text { CPE } \\
\text { d79 }\end{array}$ & $\begin{array}{l}\text { CPG } \\
\text { d79 }\end{array}$ & $\begin{array}{l}\text { REQ } \\
\text { d89 }\end{array}$ & $\begin{array}{l}\begin{array}{l}\mathrm{RE} \\
\mathrm{d} 89\end{array} \\
\end{array}$ & $\begin{array}{l}\mathrm{ReG} \\
\mathrm{d} 89\end{array}$ & $\begin{array}{l}\text { CP } \\
\text { d89 }\end{array}$ & $\begin{array}{l}\text { CPC } \\
\text { d89 }\end{array}$ & $\begin{array}{l}\text { CPG } \\
\text { d89 }\end{array}$ & ED & GR & GD & TGW \\
\hline GY79 & $0.46 * *$ & -0.40 ** & $0.43^{* * *}$ & $0.81^{* * * *}$ & $0.56^{* * * *}$ & $0.59 * * *$ & 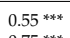 & -0.22 & $-0.35 *$ & -0.55 ** & -0.49 *** & -0.55 *** & -0.55 ** & $0.54 * *$ & $0.39 *$ & $0.55^{* *}$ & $0.83 * * *$ & $0.35^{*}$ & 0.32 & -0.73 *** \\
\hline GY89 & 1.00 & $0.1^{* * * * *}$ & $\begin{array}{l}0.23 \\
0.21\end{array}$ & $0.70^{* * * * *}$ & $0.73 * * * *$ & $0.77^{* * * *}$ & $0.75^{* * * *}$ & $-0.6^{6 * * * * *}$ & $-0.76^{* * * * *}$ & $-0.75 * * *$ & -0.53 *** & $-0.506 * *$ & $-0.63^{* * * *}$ & $0.86^{* * * * *}$ & $0.73 * * * *$ & 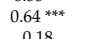 & $0.68 * 0 * * *$ & $0.58 * * * *$ & $0.95^{* * * * *}$ & $-0.79 * * *$ \\
\hline $\begin{array}{c}\text { dGY899 } \\
\text { T799v }\end{array}$ & & & $\begin{array}{l}-0.14 \\
1.00\end{array}$ & $\begin{array}{c}0.02 \\
0.37 *\end{array}$ & $\begin{array}{c}0.26 \\
-0.13\end{array}$ & $\begin{array}{c}0.25 \\
-0.12\end{array}$ & $\begin{array}{c}0.30 \\
0.013\end{array}$ & $\begin{array}{l}-0.49 * * * \\
0.43 *\end{array}$ & $\begin{array}{l}-0.48 * * * \\
0.07\end{array}$ & -0.30 & ${ }_{0.3 *^{*}}^{-0.12}$ & $\begin{array}{l}-0.10 \\
027\end{array}$ & $\begin{array}{l}-0.18 \\
0.28\end{array}$ & $0.41 *$ & $0.42^{*} *$ & $\begin{array}{l}0.18 \\
-028\end{array}$ & -0.02 & $0.90 * * *$ & $0.70^{* * *}$ & -0.17 \\
\hline 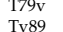 & & & & $\begin{array}{l}0.37 * \\
100\end{array}$ & $\begin{array}{l}-0.13 \\
0.66 * *\end{array}$ & $\begin{array}{l}-0.12 \\
0.69 * *\end{array}$ & $\begin{array}{l}-0.13 \\
0.67^{* * *}\end{array}$ & $\begin{array}{c}0.34 * * \\
-0.43 * *\end{array}$ & $\begin{array}{l}0.07 \\
-0.55 * *\end{array}$ & $\begin{array}{l}0.13 \\
-0.67 * * *\end{array}$ & $\begin{array}{c}0.36^{*} \\
-0.73 * *\end{array}$ & $\begin{array}{c}0.27 \\
-0.27 * * *\end{array}$ & $\begin{array}{c}0.28 \\
-0.78 * * *\end{array}$ & $\begin{array}{l}-0.1010 \\
0.82 * * *\end{array}$ & $\begin{array}{l}-0.04 * * \\
0.66 * *\end{array}$ & $\begin{array}{l}-0.28 \\
0.78 * 4 *\end{array}$ & $\begin{array}{l}0.24 \\
0.91 * * *\end{array}$ & $\begin{array}{l}-0.05 \\
-0.05\end{array}$ & $\begin{array}{l}0.14 \\
0.63 * * *\end{array}$ & $\begin{array}{l}-0.22 \\
-0.84 * *\end{array}$ \\
\hline $\begin{array}{l}\text { RES979 } \\
\text { REQ79 }\end{array}$ & & & & & 1.00 & $0.99 * * *$ & $\begin{array}{l}0.67=0 \\
1.00 * *+2\end{array}$ & 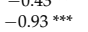 & $\begin{array}{l}-0.053 \\
-0.95 * *\end{array}$ & $\begin{array}{l}-0.67 \\
-1.00 * * *\end{array}$ & $\begin{array}{l}-0.736 * t \\
-0.76 * t\end{array}$ & 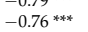 & $\begin{array}{l}-0.78 \text { - } \\
\end{array}$ & $\begin{array}{l}0.82 \\
0.86 * *\end{array}$ & $\begin{array}{l}0.06 \\
0.82 * * *\end{array}$ & 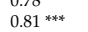 & $\begin{array}{l}0.91 \\
0.73 * *\end{array}$ & $\begin{array}{c}-0.05 \\
0.18\end{array}$ & $\begin{array}{l}0.63 \\
0.67 * * *\end{array}$ & $\begin{array}{l}-0.84 \\
-0.78 * *\end{array}$ \\
\hline RE79 & & & & & & 1.00 & $0.99 * *$ & $-0.90^{* * * *}$ & $-0.92^{* * *}$ & $\begin{array}{l}-1.0 .09 * * * \\
-0.96 *\end{array}$ & $\begin{array}{l}-0.78 * * * \\
-0.77^{* *}\end{array}$ & 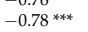 & $\begin{array}{l}-0.04 * * * \\
-0.8 *\end{array}$ & $\begin{array}{l}0.80 * * * * \\
0.87 *\end{array}$ & $\begin{array}{l}0.85 * * * * \\
0 .\end{array}$ & 0 & $0.77 * * *$ & $\begin{array}{l}0.18 \\
0.16\end{array}$ & $0.67 * * *$ & $\begin{array}{l}-0.10+* * * \\
-0.80\end{array}$ \\
\hline ReE79 & & & & & & & 1.00 & $-0.94^{*+*}$ & $-0.95^{* * * *}$ & 1.00 & $-0.76 * * *$ & $-0.77^{* * * *}$ & $-0.81^{* * *}$ & $0.86^{* * * *}$ & $0.84 * * *$ & $0.817 *+4$ & $0.72^{* * * *}$ & 0.22 & $0.69 * * *$ & $-0.78^{* * *}$ \\
\hline $\begin{array}{l}\text { CP79 } \\
\text { CPF9 }\end{array}$ & & & & & & & & 1.00 & 0.96 & $0.94 * * * *$ & 0.08 & 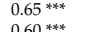 & $0.71 * * * *$ & $-0.76 * * * * *$ & 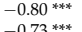 & $\begin{array}{l}-0.711^{* * *} \\
-0.66 * *\end{array}$ & $-0.50 * * * *$ & $-0.37 *$ & $\begin{array}{l}-0.65 * * * * * * * * \\
-0.7 * 7 * *\end{array}$ & $0.59 * * *$ \\
\hline $\begin{array}{c}\text { CPEF9 } \\
\text { CP9 }\end{array}$ & & & & & & & & & & 0.950 & 0.006 & 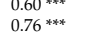 & $0.66=$ & $-0.77 * * * * *$ & $\begin{array}{l}-0.73 * 3 * * \\
-0.84 * * 4\end{array}$ & 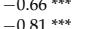 & 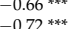 & $\begin{array}{l}-0.31 \\
-0.22\end{array}$ & $\begin{array}{l}-0.72 \% * * * * \\
-0.6 \% * *\end{array}$ & 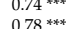 \\
\hline $\begin{array}{l}\text { REQ89 } \\
\text { Re }\end{array}$ & & & & & & & & & & & 1.00 & $\begin{array}{l}0.16 \\
0.99 * *+*\end{array}$ & $\begin{array}{l}0.81 \\
0.99 * *\end{array}$ & $\begin{array}{l}-0.98 * * * * \\
-0.90 *\end{array}$ & $\begin{array}{l}-0.84 \\
-0.93 * * *\end{array}$ & $\begin{array}{l}-0.81 \\
-0.99\end{array}$ & $\begin{array}{l}-0.72 \\
-0.74 * *\end{array}$ & $\begin{array}{c}-0.22 \\
0.01\end{array}$ & $\begin{array}{l}-0.69 \\
-0.53 * *\end{array}$ & $\begin{array}{l}0.87 \\
0.68 * *\end{array}$ \\
\hline RE89 & & & & & & & & & & & & 1.00 & $0.99 * * *$ & $-0.90^{* * *}$ & $-0.92 * * *$ & $\begin{array}{l}-0.99 \\
-0.4 \times 4\end{array}$ & $-0.79 * * * *$ & 0.03 & $-0.56 * * *$ & $0.73^{* * *}$ \\
\hline Res9Z & & & & & & & & & & & & & 1.00 & $-0.94^{* * *}$ & $-0.95 * * *$ & -1.00 & 0.01 & -0.11 & & 0.03 \\
\hline CPZ89 & & & & & & & & & & & & & & & & & -0.01 & 0.11 & & -0.03 \\
\hline $\mathrm{ED}$ & & & & & & & & & & & & & & & & & 1.00 & 0.14 & $0.62 * * *$ & -0.10 \\
\hline $\begin{array}{c}\mathrm{Gr} \\
\mathrm{GD}\end{array}$ & & & & & & & & & & & & & & & & & & & $\begin{array}{l}0.69 * * * * \\
1.00\end{array}$ & $\begin{array}{l}-0.10 \\
-0.71^{* * * *}\end{array}$ \\
\hline
\end{tabular}

$* * *, * *$, and $*$ indicate significant differences at $p<0.001, p<0.01$, and $p<0.05$, respectively; n.s. $=$ not significant. Legend: T58, T79, T89-total wheat biomass at BBCH 58, 79, 89; GY79, GY89-grain yield at BBCH 79 and 89; dGY89-grain yield increment in the period BBCH 79-89; T79v, T89v, total vegetative biomass of wheat; REQ-remobilization quota; RE—remobilization efficiency; ReG—contribution of remobilized dry matter in the grain yield; $\mathrm{CP} —$ current photosynthesis; CPE—efficiency of current photosynthesis CPG-contribution of $\mathrm{CP}$ in the grain yield; $\mathrm{d} 79$, d89-growth stages of winter wheat in accordance with the BBCH scale, referring to the respective periods of $\mathrm{BBCH} 58-\mathrm{BBCH} 79$ and $\mathrm{BBCH}$ 79-BBCH 89; ED—ears density; GR—grain per ear; GD—grain density; TGW—-thousand grain weight. 


\section{References}

1. Hunter, M.C.; Smith, R.G.; Schipanski, M.E.; Atwood, L.W.; Mortensen, D.A. Agriculture in 2050: Recalibrating targets for sustainable intensification. BioScience 2017, 67, 386-391. [CrossRef]

2. Ray, D.K.; Ramankutty, N.; Mueller, N.D.; West, P.C.; Foley, J.A. Recent patterns of crop yield growth and stagnation. Nat. Commun. 2012, 3, 1293. [CrossRef] [PubMed]

3. Shewry, P.R.; Hey, S.J. The contribution of wheat to human diet and health. Food Energy Sec. 2015, 493, 178-202. [CrossRef]

4. Available online: https://www.guinnessworldrecords.com/world--records/highest--wheat--yield (accessed on 18 November 2021).

5. Supit, I.; van Diepen, C.A.; de Wit, A.J.W.; Kabat, P.; Baruth, B.; Ludwig, F. Recent changes in the climatic yield potential of various crops in Europe. Agric. Syst. 2010, 103, 683-694. [CrossRef]

6. FAOSTAT. 2021. Available online: https://www.fao.org/statistics (accessed on 18 November 2021).

7. Klepper, B.; Rickman, R.W.; Waldman, S.; Chevalier, P. The physiological life cycle of wheat: Its use in breeding and crop management. Euphytica 1998, 100, 341-347. [CrossRef]

8. Rickman, R.W.; Waldman, S.E.; Klepper, B. MODWht3: A development driven wheat growth simulation. Agron. J. 1996, 88, 176-185. [CrossRef]

9. Fisher, R.A. Wheat physiology: A review of recent developments. Crop Pasture Sci. 2011, 62, 95-114. [CrossRef]

10. Serrago, R.A.; Alzueta, I.; Savin, R.; Slafer, G.A. Understanding grain yield responses to source-sink ratios during grain filling in wheat and barley under constraining environments. Field Crop. Res. 2013, 150, 42-51. [CrossRef]

11. Gaju, O.; Allard, V.; Martre, P.; Le Gouis, J.; Moreau, D.; Bogard, M.; Hubbart, S.; Foulkes, M.J. Nitrogen partitioning and remobilization in relation to leaf senescence, grain yield and grain nitrogen concentration in wheat cultivars. Field Crop. Res. 2014, 155, 213-223. [CrossRef]

12. Sadras, V.O.; Lawson, C. Genetic gain in yield and associated changes in phenotype, trait plasticity and competitive ability of South Australian wheat varieties released between 1958 and 2007. Crop Pasture Sci. 2011, 62, 533-549. [CrossRef]

13. Slafer, G.A.; Elia, M.; Savin, R.; Garcia, G.A.; Terrile, I.I.; Ferrante, A.; Miralles, D.J.; González, F.G. Fruiting efficiency: An alternative trait to further rise in wheat yield. Food Energy Sec. 2015, 4, 92-109. [CrossRef]

14. Kong, L.G.; Xie, Y.; Hu, L.; Feng, B.; Li, S.D. Remobilization of vegetative nitrogen to developing grain in wheat (Triticum aestivum L.). Field Crop. Res. 2016, 196, 134-144. [CrossRef]

15. Farooq, M.; Hussainf, M.; Siddique, K.H.M. Drought stress in wheat during flowering and grain-filling periods. Crit. Rev. Plant Sci. 2014, 33, 331-349. [CrossRef]

16. Duan, J.; Wu, Y.; Zhou, Y.; Ren, X.; Shao, Y.; Feng, W.; Zhu, Y.; Wang, Y.; Guo, T. Grain number response to pre-anthesis dry matter and nitrogen in improving wheat yield in the Huang-Huai Plain. Sci. Rep. 2018, 8, 7126. [CrossRef] [PubMed]

17. Sinclair, T.R.; Jamieson, P.D. Yield and grain number of wheat: A correlation or causal relationship? Authors' response to „The importance of grain or kernel number in wheta: A replair to Sinclair and Jamieson by R.A. Fisher. Field Crop. Res. 2008, 105, 22-26. [CrossRef]

18. Xie, Q.; Mayes, S.; Sparkes, D.L. Preanthesis biomass accumulation and plant organs defines yield components in wheat. Eur. J. Agron. 2016, 81, 15-26. [CrossRef]

19. Blum, A. Improving wheat grain filling under stress by stem reserve mobilization. Euphytica 1998, 100, 77-83. [CrossRef]

20. Masoni, A.; Ercoli, L.; Mariotti, M.; Arduini, I. Post-anthesis accumulation and remobilization of dry matter, nitrogen and phosphorus in durum wheat as affected by soil type. Eur. J. Agron. 2007, 26, 179-186. [CrossRef]

21. Ehdaie, B.; Alloush, G.; Madore, M.; Waines, J. Genotypic variation for stem reserves and mobilization in wheat: II.Postanthesis changes in internode water-soluble carbohydrates. Crop Sci. 2006, 46, 2093-2103. [CrossRef]

22. Ma, J.; Huang, G.B.; Yang, D.L.; Chai, Q. Dry matter remobilization and compensatory effects in various internodes of spring wheat under water stress. Crop Sci. 2014, 53, 331-339. [CrossRef]

23. Zhang, J.; Chen, W.; Dell, B.; Vergauwen, R.; Zhang, X.; Mayer, J.E.; Van den Ende, W. Wheat genotypic variation in dynamic fluxes of WSC components in different stem segments under drought during grain filling. Front. Plant Sci. 2015, 6, 624. [CrossRef]

24. Liu, E.K.; Mei, X.R.; Yan, C.R.; Gong, D.Z.; Zhang, Y.Q. Effects of water stress on phytosynteetic characteristics, dry matter translocation and WUE in two winter wheat genotypes. Agric. Water Manag. 2016, 167, 75-85. [CrossRef]

25. Grafton, R.Q.; Williams, J.; Jiang, Q. Food and water gaps to 2050: Preliminary results from the global food and water systems (GFWS) platform. Food Sec. 2015, 7, 209-220. [CrossRef]

26. Liu, J.; Williams, J.R.; Zehnder, A.J.B.; Yang, H. GEPIC—modelling wheat yield and crop water productivity with high resolution on a global scale. Agric. Syst. 2007, 94, 478-493. [CrossRef]

27. Johnston, A.M.; Bruulsema, T.W. 4R nutrient stewardship for improved nutrient use efficiency. Procedia Eng. 2014, 83, 365-370. [CrossRef]

28. Ma, G.; Liu, W.; Li, S.; Zhang, P.; Wang, C.; Lu, H.; Wang, L.; Xie, Y.; Ma, D.; Kang, G. Determining the optimal N input to improve grain yield and Quality in winter wheat with reduced apparent $\mathrm{N}$ loss in the North China. Front. Plant Sci. 2019, 10, 181. [CrossRef]

29. Kostić, M.M.; Tagarakis, A.C.; Ljubičić, N.; Blagojević, D.; Radulović, M.; Ivoševic, B.; Rakić, D. The Effect of N Fertilizer Application Timing on Wheat Yield on Chernozem Soil. Agronomy 2021, 11, 1413. [CrossRef]

30. Schauberger, B.; Ben-Ari, T.; Makowski, D.; Kato, T.; Kato, H.; Ciais, P. Yield trends, variability and stagnation analysis of major crops in France over more than a century. Sci. Rep. 2018, 8, 16865. [CrossRef] 
31. Vargas, M.; Glaz, B.; Alvarado, G.; Pietragalla, J.; Morgounov, A.; Zelenskiy, Y.; Crossa, J. Analysis and Interpretation of Interactions in Agricultural Research. Agron. J. 2015, 107, 748-762. [CrossRef]

32. Tabak, M.; Lepiarczyk, A.; Filipek-Mazur, B.; Lisowska, A. Efficiency of Nitrogen Fertilization of Winter Wheat Depending on Sulfur Fertilization. Agronomy 2020, 10, 1304. [CrossRef]

33. Klikocka, H.; Marks, M.; Barczak, B.; Szostak, B.; Podleśna, A.; Podleśny, J. Response of spring wheat to NPK and S fertilization. The content and uptake of macronutrients and the value of ionic ratios. Open Chem. 2018, 16, 1059-1065. [CrossRef]

34. Grzebisz, W. Crop response to magnesium fertilization as affected by nitrogen supply. Plant Soil 2013, 368, 23-39. [CrossRef]

35. Wang, Z.; Hassan, M.U.; Nadeem, F.; Wu, L.; Zhang, F.; Li, X. Magnesium fertilization improves crop yield in most prodyuction systems: A meta-analysis. Front. Plant Sci. 2020, 10, 1727. [CrossRef]

36. Kabała, C.; Charzyński, P.; Chodorowski, J.; Drewnik, M.; Glina, B.; Greinert, A.; Hulisz, P.; Jaknkowski, M.; Jonczak, J.; Łabaz, B.; et al. Polish Soil Classification: Principles, classification scheme and correlation. Soil Sci. Annu. 2019, 70, 71-97. [CrossRef]

37. Meier, U. (Ed.) Growth stages of mono- and dicotyledonous plants. In BBCH Monograph, 4th ed.; Federal Biological Research Centre for Agriculture and Forestry, Julius Kuhn-Institut: Quedlinburg, Germany, 2018; p. 204.

38. Papakosta, D.K.; Gagianas, A.A. Nitrogen and dry matter accumulation, remobilization, and losses for Mediterranean wheat during grain filling. Agron. J. 1991, 83, 864-870. [CrossRef]

39. Lu, D.; Lu, F.; Pan, J.; Cui, Z.; Zou, C.; Chen, X.; He, M.; Wang, Z. The effects of cultivar and nitrogen management on wheat yield and nitrogen use efficiency in the North China Plain. Field Crop. Res. 2015, 171, 157-164. [CrossRef]

40. Belete, F.; Dechassa, N.; Molla, A.; Tana, T. Effect of split application of different $\mathrm{N}$ rates on productivity and nitrogen use effciency of bread wheat (Triticum aestivum L.). Agric. Food Sec. 2018, 7, 92. [CrossRef]

41. Grzebisz, W.; Diatta, J. Constrains and solutions to maintain soil productivity, a case study from Central Europe. In Soil Fertility Improvement and Integrated Nutrient Management-A Global Perspective; Whalen, J., Ed.; InTech: London, UK, $2012 ;$ pp. 159-183.

42. Würschum, T.; Leiser, W.L.; Langner, S.M.; Tucker, M.R.; Longin, C.F.H. Phenotypic anf genetic analysis of spike and kernel characteristics in wheat reveals long-term genetic trends of grain yield components. Theor. Appl. Genet. 2018, 131, 2071-2084. [CrossRef]

43. Hodgkinson, L.; Dodd, I.C.; Binley, A.; Ashton, R.W.; White, R.P.; Watts, C.W.; Whalley, W.R. Root growth in field grown winter wheat: Some effects of soil conditions, season and genotype. Eur. J. Agron. 2017, 91, 74-83. [CrossRef] [PubMed]

44. Shearman, V.J.; Sylvester-Bradley, R.; Scott, R.K.; Foulkes, M.J. Physiological processes associated with wheat yield progress in the UK. Crop Sci. 2005, 45, 175-185.

45. Fisher, R.A. The importance of grain or kernel number in wheat: A reply to Sinclair and Jamieson. Field Crop. Res. 2008, 105, 15-21. [CrossRef]

46. Körner, C. Paradigm shift in plant growth control. Curr. Opin. Plant Biol. 2015, 25, 107-114. [CrossRef] [PubMed]

47. Guo, Z.; Chen, D.; Schnurbusch, T. Plant and floret growth at distinct developmental stages during the stem elongation phase in wheat. Front. Plant Sci. 2018, 9, 330. [CrossRef] [PubMed]

48. Bindraban, P.S.; Sayre, K.D.; Solismoya, E. Identifying factors that determine kernel number in wheat. Field Crop. Res. 1998, 58, 223-234. [CrossRef]

49. Gebbing, T.; Schnyder, H. Pre-anthesis reserve utilization for protein and carbohydrate synthesis in grains of wheat. Plant Physiol. 1999, 121, 871-878. [CrossRef]

50. Estrada-Campuzano, G.; Slafer, G.A.; Miralles, D.J. Differences in yield, biomass and their components between triticale and wheat grown under contrasting water and nitrogen environments. Field Crop. Res. 2012, 128, 167-179. [CrossRef]

51. Van Herwaarden, A.F.; Farquhar, G.D.; Angus, J.F.; Richards, R.A.; Howe, G.N. 'Haying-off' the negative grain yield response of dryland wheat to nitrogen fertiliser. I. Biomass, grain yield, and water use. Aust. J. Agric. Res. 1998, 49, 1067-1081. [CrossRef]

52. Schnyder, H. The role of carbohydrate storage and redistribution in the source-sink relations of wheat and barley during grain filling. A review. New Phytol. 1993, 123, 233-245. [CrossRef]

53. Liang, X.; Liu, Y.; Chen, Y.; Adams, C. Late-season photosynthetic rate and senescence were associated with grain yield in winter wheat of diverse origin. J. Agron. Crop. Sci. 2018, 204, 1-12. [CrossRef]

54. Acreche, M.M.; Slafer, G.A. Grain weight, radiation interception and use efficiency as affected by sink-strength in Mediterranean wheats released from 1940 to 2005. Field Crop. Res. 2009, 110, 98-105. [CrossRef]

55. Tränkner, M.; Tavakol, E.; Jákli, B. Functioning of potassium and magnesium in photosynthesis, photosynthate translocation and photoprotection. Physiol. Plant. 2018, 163, 414-431. [CrossRef] [PubMed]

56. Ceylan, Y.; Kutman, U.B.; Mengutay, M.; Cakmak, I. Magnesium application to growth medium and foliage affect the starch distribution, increase the grain size and improve the seed germination in wheat. Plant Soil 2016, 406, 145-156. [CrossRef]

57. Popović, V.; Ljubičić, N.; Kostić, M.; Radulović, M.; Blagojević, D.; Ugrenović, V.; Popović, D.; Ivošević, B. Genotype $\times$ Environment Interaction for Wheat Yield Traits Suitable for Selection in Different Seed Priming Conditions. Plants 2020, 9 , 1804. [CrossRef] [PubMed]

58. Ljubičić, N.; Popović, V.; Ćirić, V.; Kostić, M.; Ivošević, B.; Popović, D.; Pandžić, M.; El Musafah, S.; Janković, S. Multivariate Interaction Analysis of Winter Wheat Grown in Environment of Limited Soil Conditions. Plants 2021, 10, 604. [CrossRef] [PubMed] 